\title{
REVIEW
}

\section{Antibacterial activity of silver nanoparticles: A surface science insight}

\section{Benjamin Le Ouay, Francesco Stellacci*}

\author{
Institute of Materials, École Polytechnique Fédérale de Lausanne (EPFL), 1015 Lausanne, Switzerland
}

Received 16 February 2015; received in revised form 31 March 2015; accepted 6 April 2015

Available online 1 May 2015

\section{KEYWORDS \\ Silver nanoparticle; Antimicrobial; Surface chemistry; Dissolution; Speciation}

\begin{abstract}
Summary Silver nanoparticles constitute a very promising approach for the development of new antimicrobial systems. Nanoparticulate objects can bring significant improvements in the antibacterial activity of this element, through specific effect such as an adsorption at bacterial surfaces. However, the mechanism of action is essentially driven by the oxidative dissolution of the nanoparticles, as indicated by recent direct observations. The role of $\mathrm{Ag}^{+}$release in the action mechanism was also indirectly observed in numerous studies, and explains the sensitivity of the antimicrobial activity to the presence of some chemical species, notably halides and sulfides which form insoluble salts with $\mathrm{Ag}^{+}$. As such, surface properties of $\mathrm{Ag}$ nanoparticles have a crucial impact on their potency, as they influence both physical (aggregation, affinity for bacterial membrane, etc.) and chemical (dissolution, passivation, etc.) phenomena. Here, we review the main parameters that will affect the surface state of Ag NPs and their influence on antimicrobial efficacy. We also provide an analysis of several works on Ag NPs activity, observed through the scope of an oxidative $\mathrm{Ag}^{+}$release.
\end{abstract}

(c) 2015 Elsevier Ltd. All rights reserved.

\section{Introduction}

With the emergence of pathogenic bacterial strains that possess a resistance toward one or several antibiotics, the medical world is in need of new classes of disinfection systems [1-5]. Silver-containing systems, and notably silver nanoparticles (Ag NPs) are to these days one of the most promising system to fill this role [6-8]. Silver as a disinfectant has (empirically) been used for several millennia

\footnotetext{
* Corresponding author. Tel.: +41 216937872.

E-mail address: Francesco.stellacci@epfl.ch (F. Stellacci).
}

$[9,10]$, and implanted as salt or nano-systems (colloids) during the 1960s, primarily for wound treatment [11]. However, comprehensive research on the antibacterial action of Ag NPs emerged around 2004 [12] and rose exponentially. Nano-silver systems present several advantages that make them very interesting for a use as antimicrobial agents. They possess a very high activity against a broad range of microbes and parasites, even when low doses are used (full growth inhibition of bacteria can occur at only a few $\mathrm{mg} / \mathrm{ml}$ ). At these doses, silver present very little systemic toxicity toward humans, and is relatively inexpensive and available. Silver has thus been incorporated within a wide variety of materials, under various forms (salts, immobilized ions or 
metallic nanoparticles), as referenced in several very complete reviews $[9,13,14]$.

Several articles have also been written to explain mechanistically the mode of action of silver nanoparticles [15-19]. However, most work focused on the empirical observations of effects that lead to the eradication of the target microbes, and very little rationalization on the general antimicrobial pathways was performed. Furthermore, our knowledge in terms of surface chemistry of Ag NPs has improved since the seminal works in the field. Notably, recent works provided very strong clues that even in the case of metallic $\mathrm{Ag}^{0} \mathrm{NPs}$, oxidation and ion release may play a preponderant role $[20,21]$. These new discoveries call for a re-evaluation of previous works with the scope of this recently acquired knowledge.

In this review we will focus on the several physical chemistry aspects that govern the mode of action of Ag NPs, and give a comprehensive overview of how these aspects can be understood through the scope of surface chemistry. As such, while they constitute a crucial aspect of the Ag NPs mode of action, description of the biochemical aspects of the antimicrobial effect would be out of the scope of this review. Only general trends will thus be described. More information can be found in excellent reviews on the subject [15-19]. Additionally, toxicity issues for humans (systemic and at the cellular (evel) are topics of primary concern related to $\mathrm{Ag}$ NPs, but will not be developed here. We invite the reader to consult pre-existing reviews on the topic [22-25]. In a first part, we will draw out the possible mechanisms that are thought to be involved in the silver antimicrobial action, and notably the role of soluble silver $(+1)$ species as the effective agent. We will then point out several phenomena that occur around metallic Ag NPs and explain their reactivity under different conditions. Then, we will show how these aspects evaluated in laboratory conditions on models can be transposed to actual systems, be it in the environment or in contact with the target micro-organisms.

\section{Mechanism of action}

One key element in the design of a more potent antibacterial system is the understanding of its mode of action. This involves two distinctive steps that will each have an impact on its efficiency. The first one is the way the system will behave in the environment of interest, where physical or chemical modifications can occur. Among these, aggregation, dissolution, RedOx (photo-)reactions, release of adsorbed silver species, adsorption or desorption of ions, molecular species or polymers, or interaction with other nanoparticles or surfaces can all have an effect on the speciation of silver, modifying this metal availability and impacting the antibacterial effect. The second step involves the way the silver-containing species interact with the bacterial cell and lead to the cellular death. This second step is thus dependent on the first one, as the nature of the silver-cell interaction is dependent on the type of silver species that are present in solution. As it is the case for most nanomaterials, the toxicity impact of different systems is thus difficult to compare from one study to the other. This impact relies on the studied organism, but also on the synthetic parameters (ligand type, washing steps, shape, size (average and dispersion), ...) and evaluation procedures (bacterial strain used, toxicity criterion (growth inhibition or full eradication), nature of the test to assess it, concentration, composition of the medium, presence of light or oxygen, ...) [26]. As most modes of action are postulated from empirical observations, and due to the profusion of organisms and condition evaluated, several disinfection pathways have been described for silver nanoparticles, and the exact mode of action remains unclear to this date.

\section{Role of $\mathrm{Ag}^{0}$}

Since the first observations of the Ag NPs antimicrobial activity, most researchers have intuitively attributed the antimicrobial activity to the presence of a $\mathrm{Ag}^{0}$ core. When put in contact with bacteria, Ag NPs tends to accumulate at the bacterial membrane, and form aggregates. In these conditions, several authors reported the diminution of the bacterial membrane integrity, and observed its perforations leading to cellular death $[12,27,28]$. However, if the antibacterial mechanism relied on the interaction between biological components and Ag NPs surface, systems of very different sizes (from $1 \mathrm{~nm}$ to several hundreds of $\mathrm{nm}$ ) [9] should not interact the same way and have the same action mechanisms. As particles of very different sizes have been seen to have antibacterial action, one can postulate that their action mechanism relies, at least partially, on a secondary specie.

Generation of reactive oxygen species (ROS) by the $\mathrm{Ag}$ NPs has also been considered a primary mode of cytotoxic action of Ag NPs [22,29]. Several studies observed a high level of ROS in cells treated with Ag NPs [30-33]. In these conditions, the cells endure a very high oxidative stress that leads to the cellular inactivation. While some authors have mentioned a catalytic role of the NPs in the formation of ROS, it has to be mentioned that these oxygen species are a natural by-product of the oxygenic respiration [34,35]. Scavenging mechanisms exists in the cell to lower their concentration, and reduce thus the oxidative stress. As such, an augmentation of the concentration of ROS can be attributed to a higher rate of formation, or to a disruption in the scavenging pathways, as will be discussed in the next section.

\section{Role of $\mathrm{Ag}^{+}$species}

Some other mechanisms give a prevalent role to $\mathrm{Ag}^{+}$species. Some systems, such as salts [36], zeolites [37] or ionomers [38], contain initially silver $(+1)$ species, and can release them by simple dissolution or ion exchange. It is not the case with metallic $\mathrm{Ag}^{0}$ nanoparticles. In this case, $\mathrm{Ag}^{+}$species release involves an oxidative dissolution of the $\mathrm{Ag}^{0}$ $\mathrm{NP}$, and thus the presence of an oxidizer. The monovalent silver species is then the proper antibacterial agent, while the nanoparticle acts as a reservoir. One key of the action of silver ions is that they possess a very high affinity for organic amines, phosphates and most notably thiols, with which they forms a quasi-covalent bond $(\mathrm{Ag}-\mathrm{S}$ binding energy being around $65 \mathrm{kcal} / \mathrm{mol}$ ) [39]. Affinity of $\mathrm{Ag}^{+}$ for selenol groups is comparable [40], but these moieties are relatively rare in the living world. Furthermore, silver can act as a bridging agent between several thiols, 
forming chains that could lead to the irreversible aggregation of the thiol-bearing molecules [41]. As thus, Ag (+1) species can cause the inactivation of biological systems bearing these moieties by forming irreversible adduct with them. Several molecules (DNA, peptides (membrane-bound or inside the cell) or cofactors) have been identified as the target of these ions, each of them explaining one effect that was observed while the bacteria was dying. However, unlike an antibiotic molecule that will target one specific component of the bacterial life-cycle, $\mathrm{Ag}^{+}$ions lacks this selectivity and will adsorb readily to any moiety toward which they have a high affinity. It is thus unlikely that only one specific pathway is causing the cellular death. A much more probable hypothesis would be that silver binds non-specifically to a wide variety of targets, perturbing simultaneously many aspects of the cell metabolism and leading to its death. Among all pathways enduring perturbation, some are very sensitive to low amount of silver species, and have thus been attributed to be the main cause of cellular death. This capability to disrupt a large variety of pathways may be one reason explaining the antibacterial action of silver nanoparticles against a very broad spectrum of micro-organisms.

In contrast with the opinion of a broad variety of metabolic pathways disrupted, several studies considered ROS generation as the mode of action of silver-containing effect to explain its cytotoxic (and thus antibacterial) effect [42]. ROS species are formed naturally by cells that present a respiratory activity, and contribute to the oxidative stress [35]. They can also be formed by photo-oxidation of water, in presence of a catalyst [43]. Cellular mechanisms are present in the cell to regulate the concentration of ROS and limit this stress. An increased concentration of ROS in a cell treated with Ag NPs can thus be due to an increased generation, or to a disruption of the regulation pathways. However, cytotoxic effect of silver ions has been observed in anaerobic conditions and in the dark, a situation where ROS cannot be evolved [44]. This would tend to rule out the exclusive impact of ROS to explain the antibacterial effect of Ag NPs. By comparing $\mathrm{Ag}^{+}$action in absence and presence of oxygenic respiration, Park et al. [45] showed that evolved ROS were involved in more than half of the antibacterial activity (Fig. 1A). It has to be mentioned that in this work the chosen concentrations $(0.5-1 \mathrm{mg} / \mathrm{L})$ were relatively low, and that the proportion of bacterial death attributable to ROS decreased with the concentration $(80 \%$ for $0.5 \mathrm{mg} / \mathrm{ml}$ and $43 \%$ for $1 \mathrm{mg} / \mathrm{ml}$ after $60 \mathrm{~min}$ of contact with $\mathrm{Ag}^{+}$). As such, ROS action may be the principal antibacterial pathway at low concentration as it involves several components very sensitive to $\mathrm{Ag}^{+}$. Other non-ROS effect may dominate at higher concentrations. While formation of ROS catalyzed by silver centers can occur (notably under UV-illumination) [46], ROS evolution in presence of $\mathrm{Ag}^{+}$can in most cases be explained by a disruption of the regulation pathways [31]. Due to their very high affinity for thiols and selenols, $\mathrm{Ag}^{+}$ions will (among several other actions) disrupt the ROS-regulation system, increasing their intracellular concentration. The loss of the ROS-regulation can be due to interaction of $\mathrm{Ag}^{+}$with the reductase enzymes (and notably glutathione peroxidases, which contains selenocysteine in their active site) or by scavenging intracellular glutathione, their usual cofactor $[47,48]$.
As such, the increased oxidative stress in presence of silver is one aspect of the antibacterial action of this metal, but it is not the only one. Measurement of the intracellular concentration of ROS should thus be perceived as monitoring one side effect of $\mathrm{Ag}^{+}$action, that correlates but cannot be substituted with a quantification of the effective antibacterial (and cytotoxic in general) action.

Having $\mathrm{Ag}^{+}$as the actual antibacterial agent of $\mathrm{Ag}^{0} \mathrm{NPs}$ systems unites this category with other silver disinfectants, in which $\mathrm{Ag}^{+}$are trapped and released. In all cases, the device acts as a silver ions reservoir and the effects are similar. Modes of actions can be extrapolated from one type of system to the others, as they all share the same active species. However, the exact nature of the system is of crucial importance, as it will influence directly the ion release and the efficiency of the system.

While a role of metallic silver nanoparticles cannot be excluded, there are some good hints that the oxidative dissolution mechanism is indeed the key step for nanoparticles antibacterial effect. As silver is a noble metal stable toward oxidation by water, dissolution requires another oxidizer to be achieved. In most studies, that role is filled by atmospheric $\mathrm{O}_{2}$ that dissolves into water. The role of this gas was first described with macroscopic objects [50] and deposits [51] that exhibited antibacterial activity when prepared in oxidative conditions, but not in inert atmosphere. This effect then observed was with $\mathrm{Ag}^{0}$ nanoparticles by Lok et al. in 2007 [20]. In this work, the authors prepared silver nanoparticles under inert atmosphere, then voluntarily oxidized their surface in a controlled manner by bubbling oxygen in the suspension. The particles and bacteria were then put in contact under inert conditions, and the bacterial growth was monitored. The native nanoparticles showed no activity, while the oxidized ones inhibited bacterial growth at concentrations above $108 \mu \mathrm{g} / \mathrm{ml}$. When stored for several days in non-degassed solvents, Ag NPs suspensions contains free $\mathrm{Ag}^{+}$ions due this oxidative dissolution, and were observed to have a higher activity [52]. The influence of the atmosphere under which the antibacterial activity tests were performed was then showed by Xiu et al. in 2012 [21] (Fig. 1B). This group showed that silver nanoparticles presented a much lower antibacterial effect when tests were performed in anoxic conditions compared to oxygenic ones. The antibacterial effect was even more pronounced if the particles were aged at open air for 10 days to let the solution aerate before the tests. Alternatively, supplementation of the culture medium with $\mathrm{AgNO}_{3}$ resulted in similar bacterial mortality, in presence or in absence of oxygen. These results tend to strongly relate the antibacterial effect of silver nanoparticles to their dissolution, and show that dissolved atmospheric oxygen was sufficient to induce high enough concentrations of $\mathrm{Ag}^{+}$to cause bacterial death. This absence of activity in anaerobic conditions has been then backed by other works (Fig. 1C) $[33,49,53]$. As tests to assess nanoparticles activity are commonly performed on aerobically grown bacteria, it can be speculated that most of the observed results are indeed attributable to ions originating form the nanoparticles dissolution rather than to a direct action of pristine nanoparticles.

Along with oxidation, another source of $\mathrm{Ag}^{+}$ions in nanoparticulate systems is the release of chemisorbed ions at the surface of the particles [54]. If a relatively mild 

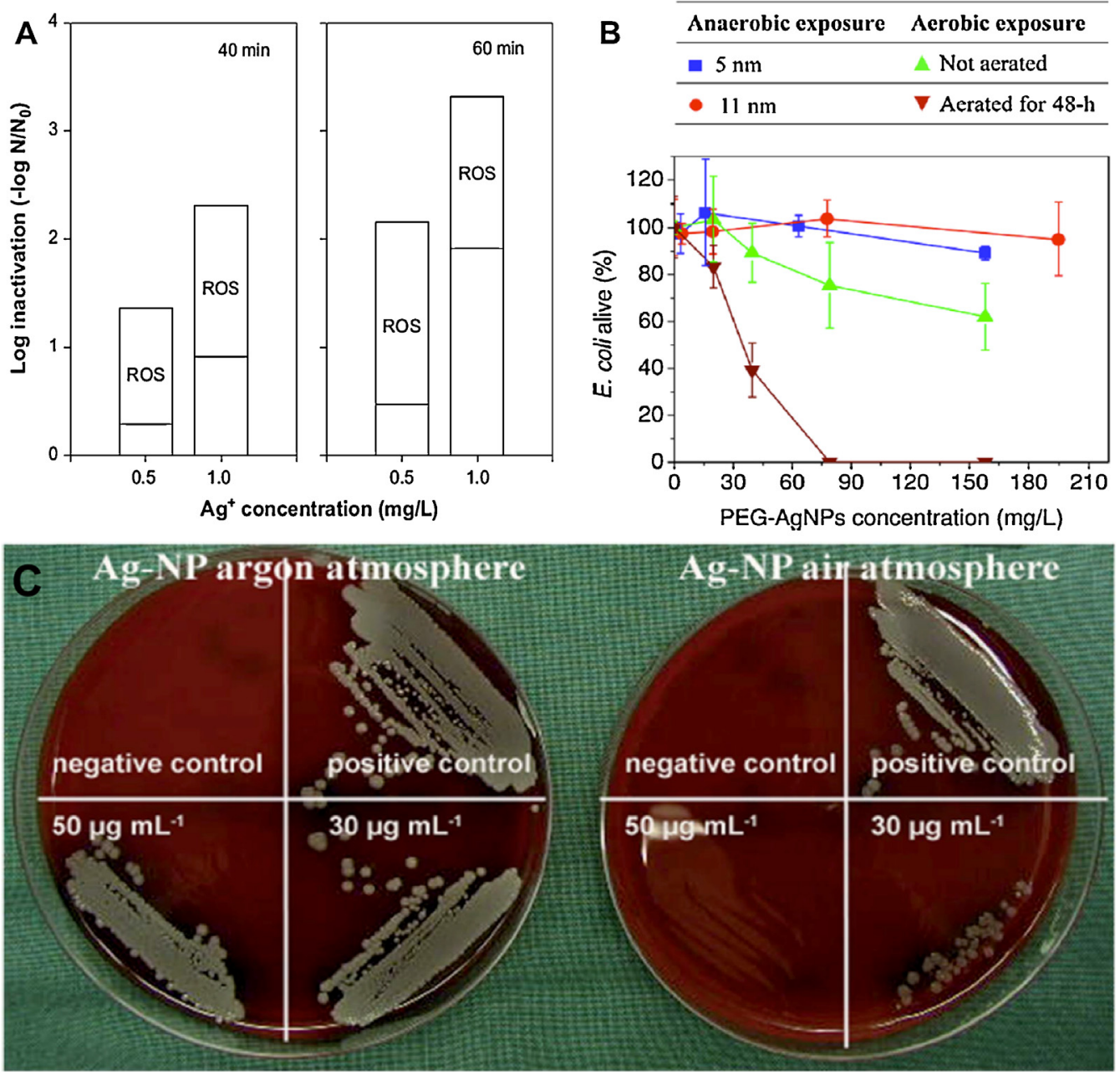

Fig. 1 Impact of the presence of $\mathrm{O}_{2}$ on the antibacterial activity of Ag NPs. (A) Proportion of bacterial death attributable to ROS generation mechanism in presence of $\mathrm{Ag}^{+}$ions. (B) Antibacterial action of Ag NPs under aerobic and anaerobic atmosphere. (C) Action of Ag NPs on culture of bacteria under Ar or air atmosphere.

(A: Adapted from [45] with permission from Elsevier, B: Adapted with permission from [21]. Copyright 2012 American Chemical Society, C: Adapted from [49] by permission of The Royal Society of Chemistry).

reducing agent (such as sodium citrate) is used for the reduction, a proportion of the original silver salt will remain in its oxidized state. This ions will remain free in solution, or be bound to the surface of the $\mathrm{Ag}^{0}$ nanoparticles, for instance through a pending group of the citrate ligands [55]. While $\mathrm{Ag}^{0}$ oxidative dissolution is the predominant way to release $\mathrm{Ag}^{+}$in solution, chemisorbed ions release can also contribute to the antibacterial effect, even in absence of an oxidizer. This effect is further increased as the nanoparticle size decreases, as they present more surface and hence potentially higher quantities of chemisorbed $\mathrm{Ag}^{+}$. Considering a density of $1 \mathrm{Ag}^{+} / \mathrm{nm}$, a geometrical calculation indicates that $5 \mathrm{~nm}$ diameter nanoparticles can adsorb about $20 \mu \mathrm{g}$ of $\mathrm{Ag}^{+}$per $1 \mathrm{mg}$ of $\mathrm{Ag}^{0}$.

Another aspect that would associate the Ag NPs action to a release of $\mathrm{Ag}^{+}$ions is the fact that some anions in solution decrease strongly the antibacterial activity [56]. $\mathrm{Ag}^{+}$is a cation that forms very poorly soluble precipitates when in presence of most anions of environmental or biological significance (with the exceptions of fairly soluble $\mathrm{AgNO}_{3}$ and $\mathrm{AgF})$. For instance, solubility of silver $(+1)$ sulfide $\left(\mathrm{Ag}_{2} \mathrm{~S}\right)$ is $140 \mu \mathrm{g} / \mathrm{L}$, silver $(+1)$ chloride $(\mathrm{AgCl})$ is $1.9 \mathrm{mg} / \mathrm{L}$ and silver (+1) phosphate $\left(\mathrm{Ag}_{3} \mathrm{PO}_{4}\right)$ is $6.5 \mathrm{mg} / \mathrm{L}$. The toxicity reduction has thus been associated to the formation of an insoluble precipitate that scavenges most of the $\mathrm{Ag}^{+}$ions from the solution and hence lowers their availability and action. Presence of sulfides is one of the most notable cases, due to the very low solubility of $\mathrm{Ag}_{2} \mathrm{~S}$. Several studies showed that presence of traces of this ion almost suppressed the biocidal activity of silver containing-systems, as seen in Fig. 2A [57-59]. Furthermore, both Reinsch et al. [58] and Levard et al. [59] showed an inhibition of the effect for $\mathrm{S}^{2-} / \mathrm{Ag}$ molar ratio below 0.5 (which corresponds to the stoichiometric conditions). This was explained by the formation of an insoluble $\mathrm{Ag}_{2} \mathrm{~S}$ layer around the $\mathrm{Ag} \mathrm{NPs}$, preventing further dissolution and hence activity. The dissolution phenomenon has thus to be related to a passivation by a silver salt layer around the nanoparticles, as will be discussed further. Chloride is another anion that is very prevalent both in 

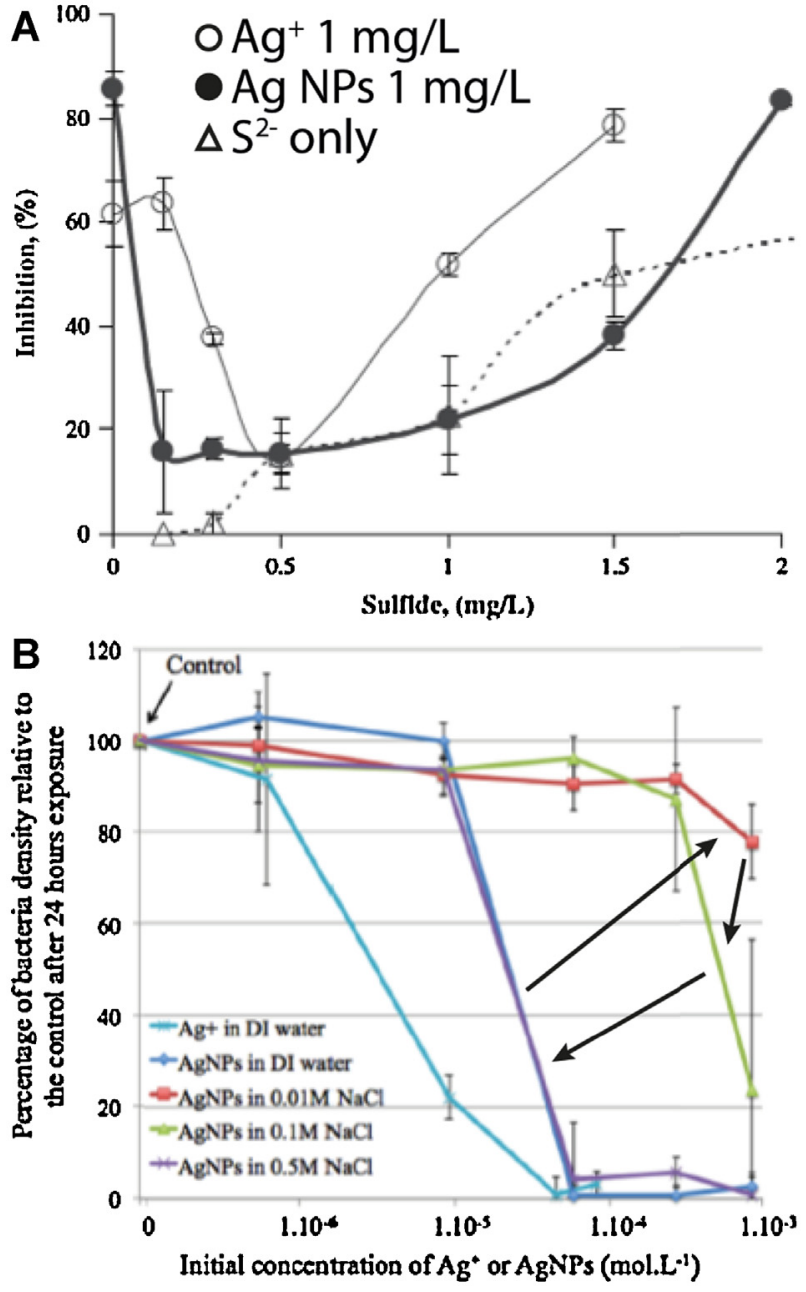

Fig. 2 Influence of added sulfide (A) and chloride (B) anions on the antibacterial action of Ag NPs. In Fig. 2B, arrows indicate the trend as the chloride concentration increases.

(A: adapted from [57] with permission from Elsevier, B: Adapted with permission from [60]. Copyright 2013 American Chemical Society).

biological or environmental systems and forms the poorly soluble precipitate $\mathrm{AgCl}$. However, in presence of excess chloride, soluble silver $(+1)$ polychloride species $\mathrm{AgCl}_{x}(x-1)-$ are formed and contribute to the antibacterial activity (Fig. 2B) [60,61]. As these species are negatively charged, it is however possible that their activity toward the cells, and notably their capability to be internalized, is different. Chloride anions have also an influence on the fate of the NPs, through passivation and aggregation promotion, and can thus lead to a more complex behavior. These effects will be discussed further in this article.

Finally, the requirement of the Ag NPs to dissolve and to release $\mathrm{Ag}^{+}$ions can contribute explaining the size and shape dependency of the nanoparticle action [62]. Most studies show indeed a size dependency of the antimicrobial activity of (quasi-spherical) nanoparticles, the smaller being the more active [63]. In these cases, the improved activity stems from an easier dissolution. As the surface per unit of mass scales like $1 / R$ (the number of particles scales like $1 / R^{3}$ and the surface like $R^{2}$, with $R$ the radius), it results that smaller

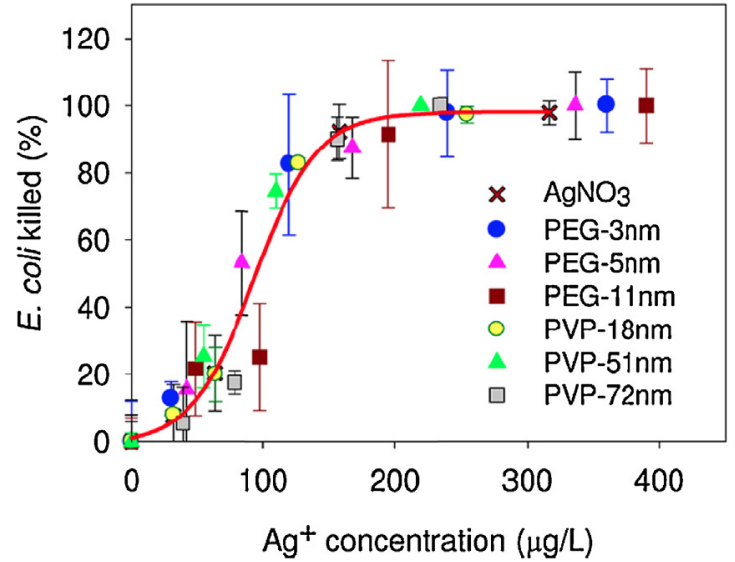

Fig. 3 Antibacterial action of several Ag NPs as a function of the $\mathrm{Ag}^{+}$ions effectively released.

(Adapted with permission from [21]. Copyright 2012 American Chemical Society).

NPs exhibit more active surface and are thus more prone to dissolution. For similar reasons, aggregated NPs expose less surface to the solvent than separated NPs, and thus possess a lower antibacterial impact [64]. While size of the NPs is a crucial parameter to determine their proper activity per unit of mass (or mole), it has been recently demonstrated by Liu et al. [65] that the released $\mathrm{Ag}^{+}$scaled well if the sample were normalized by their exposed surface. Afterwards, Xiu et al. [21] showed in 2012 that the significant parameters to evaluate the activity of silver nanoparticles were the silver released $\mathrm{as} \mathrm{Ag}^{+}$and not the amount of elemental silver introduced as nanoparticle (Fig. 3).

A shape dependency of the antimicrobial effect has also been observed. Nanoprisms and to a lower extent nanorods present more activity than nanosphere $[62,66]$ due to a higher exposure of [111] facets [67]. This has been attributed to an easier dissolution of [111] facets of silver, leading to a faster $\mathrm{Ag}^{+}$release and thus a higher activity for nanoparticles that exhibit more of these facets. The exact reason why Ag [111] facets are easier to dissolve remains to be investigated, but this effect could be due to differences in the solvation and arrangement of the ligands on this type of facets, or to an instability of $\mathrm{Ag}_{2} \mathrm{O}$ layer on $\mathrm{Ag}$ [111], with the preferential formation of suboxides layer [68].

\section{Role of the nanoparticulate objects}

Although action of $\mathrm{Ag}^{+}$appears to be a very plausible mechanism for silver nanosystems antimicrobial activity, the presence of nanoparticles could also provide some advantages and improve the potency of the system. The first advantage is that Ag NPs could act as silver ions reservoir, and provide continuously a high enough concentration of silver antibacterial species in their surroundings to maintain an activity for several days. While this effect is not relevant in most in vitro tests performed in closed conditions, it could be very useful in real application conditions, were fluid circulation could wash away active species as they are released. Furthermore, one nanoparticle immobilized close to a bacterium (or even internalized) is able to 


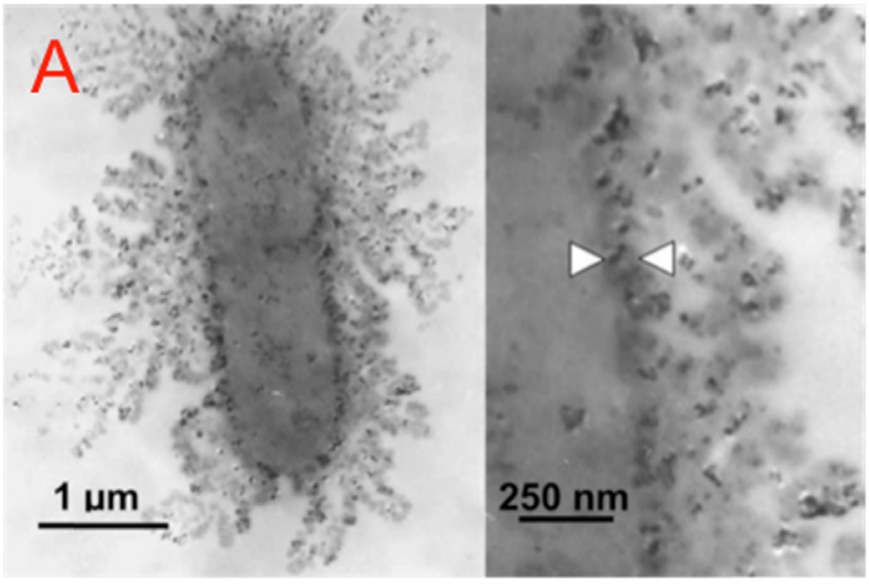

(a): control cells

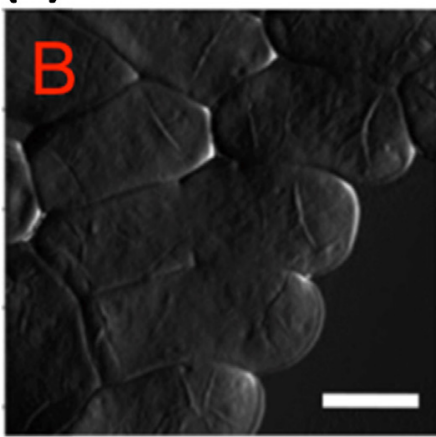

(b): cells+Ag-cit 10
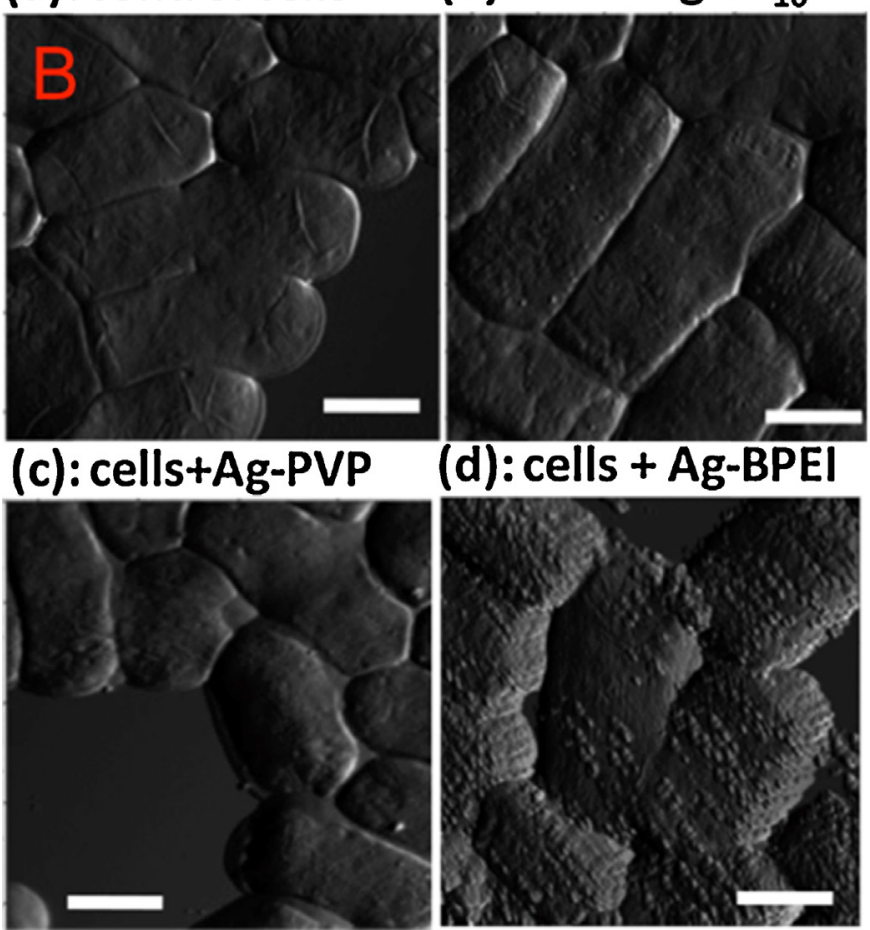

Fig. 4 Illustrations of the adsorption of Ag NPs at the surface of bacteria. (A) TEM images of bacteria adsorbing Ag NPs at their membrane. (B) AFM images of the surface of bacteria in contact with differently coated Ag NPs.

(A: Adapted from [12] with permission from Elsevier, B: Adapted with permission from [70]. Copyright 2014 American Chemical Society).

release several tens of thousands of silver atoms in its vicinity, producing a locally high concentration of antibacterial ions (Trojan horse effect) [69].

This aspect is enhanced by the capability the nanoparticles possess to adsorb at the membrane of the bacteria, as observed by Sondi et al. in 2004 (Fig. 4A) [12]. Recently, Ivask et al. [70] used Atomic Force Microscopy to detect Ag NPs at bacterial surface. They showed that positively charged branched polyethylenimine-coated (BPEI) nanoparticles had a much higher affinity toward negatively charged bacteria than commonly used citrate coated (Fig. 4B), and thus presented a higher toxicity (a similar trend in toxicity was shown earlier by El Badawy et al. [71]). However, an active role of this ligand bearing multiple amine groups on the improved antibacterial effect cannot be excluded. More generally, affinity of NPs for the surface of the cell depends on the $\zeta$-potential of the NPs (which depends on the ionic strength of the solution) and also on the exact nature of the cell envelope, including eventual presence of extracellular polymers. A comparison between different works to evaluate the real influence of the NPs-cell interaction can be difficult. It is also noteworthy to add that in the seminal work of Sondi et al., the ligand used to stabilize the nanoparticles was a poly-naphthalene sulfonate negatively charged [12]. Since bacterial membranes are themselves negatively charged, this indicates that a ligand exchange step can be involved prior or during the cell-NP interaction.

Finally, some aspects that can influence the antibacterial activity of silver nanosystems are attributable to other constituents of the system, and not to the presence of silver. For instance, nanoparticles can be prepared using ligands or compounds that possess themselves an antibacterial activity (chitosan [72], surfactants [73], etc.). The antibacterial effect is then at least partly attributable to this extra component. A synergistic effect between silver and another antibacterial agent can also happen, leading to antibacterial effects at concentrations below which none of the systems would be active if taken independently [74,75]. An antibacterial effect can also be due to the physical impact nanoparticles have on the cells (microabrasion, surface rigidification, bacterial flocculation) [76]. These effects do not rely on the chemical nature, and are thus expected to be of lower magnitude, on par with unreactive nanoparticulate systems (nanodiamonds, $\mathrm{SiO}_{2}, \mathrm{Al}_{2} \mathrm{O}_{3}$ ) [77-79].

\section{Factors involved in the control of the activity}

Although they possess a very high activity as antimicrobials, Ag NPs are complex systems. Their activity is indeed dependent on several processes, each one having an influence on the other [26]. To model an antibacterial system's activity, one has to take into account the nanoparticles transport to the bacteria, their dissolution and the speciation of silver in the surrounding environment or in the intracellular medium. For each application, the nanoparticulate system will have to be tuned properly, in order to take into account its specificities:

- Microbial strains relevant to the system, presence of eventual biofilms.

- Amount of oxidizer: Oxic, anoxic or microxic conditions.

- Composition of the medium, salinity, presence of other ligands.

- Effluent circulation: Closed system, permanent circulation or periodic renewing of the outer medium.

- Physical properties: Temperature, Convection or passive diffusive transport.

- Presence of light that can cause photoreduction of $\mathrm{Ag}(+1)$ species.

- Other parameters to consider: Innocuity for the patient or the environment, production cost, shelf-stability of the system. 
The point of this section is not to dress a list of the various conditions of application that exist for Ag NPs. Readers could refer to very complete reviews to have an overview of this field of application. Instead, we will establish a list of pertinent phenomena that have to be considered when designing a system. The reader may then apply the general advices given and adapt them to his specific requirements.

In order to develop an efficient antibacterial system, one wants it to eradicate the most bacteria, with the minimal amount of silver, while having an activity over the longest period of time. That involves releasing the ions progressively, in order to keep a low but sufficient $\mathrm{Ag}^{+}$concentration in the system. This concentration at the vicinity of the bacteria can be adjusted along three axes. (i) The first one, and most straightforward, consists simply in increasing the amount of silver used. However, given the cost of this metal, and the potential health or environmental hazards that could arise from excessive consumption of silver [42], it is preferable to focus on improving the system following the other axes. (ii) The second lever of control consists in improving the availability of the silver antibacterial species, by tuning the dissolution of the NPs. This aspect involves a control of the Ag NPs size, shape and coating [65]. It is also preferable to avoid surface passivation, formation of insoluble precipitates or aggregation of the NPs. Different aspects affecting these kinetics will be discussed in this section. (iii) The third axis involves the increase of affinity of NPs or soluble $\mathrm{Ag}^{+}$species toward the bacteria to increase locally their concentration. This can be done by control of the surface chemistry of the NPs to match the properties of the bacterial system.

One first aspect to take into account when studying nanoparticles activity is the nature of the actual objects that are present in the system. In the case of nanosilver, dissolution of initial nanoparticles to form new ones and shape-conversion are phenomena to be considered as they modify the nanoparticles distribution and hence their potential activity. Ag NPs shape-conversion was first observed by Jin et al. in 2001 [80]. In this study, silver nanospheres were converted within $70 \mathrm{~h}$ of illumination into triangular nanoplates that exhibited parallel [111] crystalline facets. The mechanism of this conversion has been described by Xue et al. [81] and involves an oxidative dissolution of $\mathrm{Ag}$ NPs, followed by a reduction of $\mathrm{Ag}^{+}$at the surface of Ag NPs seeds. Photothermal effects due to the plasmon excitation contributes to the preferential attachment of $\mathrm{Ag}$ species on the edges of the prisms and thus to their in-plane growth [82]. This mechanism involves soluble silver species and thus explains the variability in presence of bases [83] or chlorides [84]. In some cases, nucleation can happen instead of growth on pre-existing seeds, leading to the formation of new nanoparticles. As such, Glover et al. observed the progressive formation of small Ag NPs (diameter: $5-10 \mathrm{~nm})$ around bigger $(75 \mathrm{~nm})$ ones deposited on amine-treated glass [85]. Most notably, this study showed also that the surface of macroscopic silver object (such as cutlery or jewellery) could also dissolve and lead to the formation of nanoparticle, contributing to their antibacterial action. Dissolution/reformation of $\mathrm{Ag}$ NPs was also observed in presence of humic acid, and may be a phenomenon relevant in environmental conditions $[86,87]$.
As mentioned in section "Role of $\mathrm{Ag}^{+}$species", the mode of action of silver-containing disinfection systems involves very probably their dissolution and the release of $\mathrm{Ag}^{+}$ions. Tuning the physical parameters (size, shape and exposed facets) during the preparation of nanoparticles is the primary way to control this dissolution kinetics. In the case of quasi-spherical nanoparticles, the nanoparticles dissolution behavior will be affected by the nanoparticle radius in several ways, either related to thermodynamic or kinetic considerations.

The first aspect is of thermodynamic nature, and relates the solubility to the radius of nanoparticles. Indeed, as its radius decreases, the curvature of a particle increases, which increases its surface tension. It results that nanoparticulate systems have a higher Gibbs energy than systems constituted of the same mass of bulk material. Thus, when in equilibrium with a solvent, the amount of dissolved species has to be higher to compensate this destabilization, resulting in a higher solubility of the material. This phenomenon is described by the Ostwald-Freundlich Eq. (1) [88].

$s=s_{0} \exp \left(\frac{2 \gamma V_{\text {atom }}}{k_{B} T R}\right)=s_{0} \exp \left(\frac{R_{c}}{R}\right)$

with $s$ the solubility of $\mathrm{Ag}(0)$ in the NPs, $s_{0}$ the solubility of $A g(0)$ in the bulk phase (i.e. with a flat surface), $\gamma$ the surface tension of the NPs material, $V_{\text {atom }}$ the volume occupied by an atom (or one dissolving entity in general), $k_{B}$ the Boltzmann constant, $T$ the temperature and $R$ the radius of the nanoparticles. $R_{c}=\left(2 \gamma V_{\text {atom }}\right) /\left(k_{B} T R\right)$ is a critical radius obtained by identifying the terms in the exponential.

Its validity has been attested experimentally by several studies, using nanoparticles of organic or inorganic nature $[89,90]$ and demonstrated recently by $\mathrm{Ma}$ et al. for $\mathrm{Ag}$ NPs [91]. It is however worth mentioning that solubility is a thermodynamical aspect that describes systems at the equilibrium. Thus, while it describes what quantity will be released by nanoparticles, this does not describes how fast silver ions will be released before reaching this equilibrium.

The size of nanoparticles will also have an influence on kinetic aspect, and notably on their dissolution rate. For a given mass of material, well-dispersed nanoparticles will indeed have a higher surface of contact with the surrounding medium. As dissolution rate scales with the surface, it results that finely divided material will dissolve faster than a coarser system would. However, it has also to be remembered that as nanoparticles dissolution is happening, their sizes (and thus their exposed surfaces) decrease. Under the reasonable assumption that the reaction speed is proportional to the exposed surface, and that dissolution is the limiting reaction step, calculations indicates that the NPs are etched at a constant rate, their radius decreasing linearly toward time, as demonstrated for instance by Rimer et al. [92]. Integration of these values indicates that the concentration of released $\mathrm{Ag}^{+}$follow a polynomial law of the third order, as observed by Espinoza et al. [93]. Other reaction, such as passivation or reprecipitation, could lead to a different reaction law. Furthermore, as the particle dissolves, its surface tension increases, leading to a less stable system, and transition states of higher energy. Factoring this effect lead to a non-analytically solvable system. 
Once again, it has to be remembered that these considerations were related to the ideal system of the spherical liquid drop model for nanoparticles. While it has been shown to be a good approximation of the behaviors, this model bears some limitations. First, the ligand shell around the nanoparticles may modify the surface tension of the system and thus apparent solubility. Furthermore, actual metal nanoparticles (even quasi-spherical ones) will usually exhibit crystal facets, with different surface energies and ligand stability. Finally, as the radius decreases, the nanoparticulate system becomes constituted of a relatively low number of atoms, and will behave as a molecular species with well-defined (and finite) energy levels [94] while the model erroneously predicts an almost infinite surface tension.

While some antimicrobial systems, such as Ag-loaded zeolite, polyelectrolyte and salt nanoparticles are built around Ag (+1) species and can release them as such, it is not the case of silver nanoparticles, where most of the silver is in its metallic Ag (0) state. In that case, the release of $\mathrm{Ag}^{+}$requires a preliminary oxidation step, and dissolved atmospheric dioxygen acts as the oxidizer in most systems. This phenomenon was studied extensively by $\mathrm{Ho}$ et al. in 2011 [95], showing that the reaction followed a first order in $\left[\mathrm{Ag}^{0}\right]$ and $\left[\mathrm{O}_{2}\right]$. These order where found to be independent of the nanoparticle size (from 5 to $20 \mathrm{~nm}$ ), while the apparent reaction constant $k_{\text {app }}$ increased with the diameter decrease, accounting for an easier dissolution of smaller nanoparticles. In addition, this study was performed using Tris-HOAc system as a buffer (Tris: tris(hydroxymethyl)aminomethane), and indicated an active role of this amine-bearing molecule in the dissolution, with formation of $\left[\mathrm{Ag}(\mathrm{Tris})_{2}\right]^{+}$complex. The reaction speed increased exponentially with the $\mathrm{pH}$ (ranging from 7.5 to 8.5), then reached a plateau for $\mathrm{pH}$ above 9 (Fig. 5A). This value of transition is incidentally slightly higher than the pKa of Tris $\left(8.07\right.$ at $\left.25^{\circ} \mathrm{C}\right)$. This could indicate that the amine form of Tris is acting for the dissolution of the Ag NPs, while its ammonium form plays no role. This result can be put in relationship with the increased solubility (and thus antibacterial activity) of Ag NPs in presence of ammonia [96]. Alternatively, Liu et al. and Peretyazhko et al. showed the inverse trend, with an increasing solubility with the decreasing $\mathrm{pH}$ (range 4-9) in a buffer that did not contain amines (Fig. 5B) [97,98].

The oxidative dissolution process of Ag NPs is thus likely to involves reaction of $\mathrm{O}_{2}$ at the Ag surface, followed by the formation of a layer of $\mathrm{AgO}_{x}(\mathrm{OH})_{y}$ (the exact nature of the oxide layer could differ from the common bulk $\mathrm{Ag}_{2} \mathrm{O}$ due to size effects, ligand influence and epitaxial constraints) [68]. According to Sotiriou et al. [101], this oxide layer comprises only between one and two atomic layers of $\mathrm{Ag}$ atoms, while the core is still constituted of metallic silver. This layer passivates the surface, and needs to be dissolved in order to allow further oxidation of $\mathrm{Ag}^{0}$ core. As such, a slightly acidic $\mathrm{pH}$ will increase the solubility of the oxide layer and allow a faster $\mathrm{Ag}^{+}$release (and hence a higher antibacterial activity). Alternatively, other additives can contribute to the formation of soluble silver $(+1)$ species, and thus to the dissolution of the passivation layer. As mentioned before, ammonia and molecules bearing primary or secondary amines can contribute to the oxide layer dissolution if they are in their deprotonated form, but not if they are protonated. Ag NPs dissolution rate in presence of such amines will thus be very sensitive to the $\mathrm{pH}$ for values close to their $\mathrm{pKa}$, with a sigmoidal shape that can be related to the fraction of amine that is deprotonated [95].

The role of organic thiols (and among them cysteine and glutathione) in the dissolution of Ag NPs is complex, with different regimes depending on the concentration. These species are particularly noticeable, as they will bind strongly to the surface of $\mathrm{Ag}^{0}$ NPs. This bond is very stable, and thiols are one of the few species susceptible to displace a significant amount of other thiols or sulfide ions from a $\mathrm{Ag}_{2} \mathrm{~S}$ surface. If the thiol concentration is too low, a thiolate ligand shell forms around the nanoparticle and protects it from further oxidation, as does sulfide [65]. This passivation will reduce considerably the antibacterial effect of the silver nanoparticles. However, if the thiol groups provide a sufficient solubility, silver can quantitatively be converted into soluble silver thiolates. As such, the Ag NP surface is not passivated anymore, but can release Ag $(+1)$ species. These soluble species can then diffuse toward the target cells, where further thiol-exchange with bio-molecules can lead to their anti-microbial action. In 2013, Gondikas et al. [100] showed that a high concentration of cysteine (50 molar equivalent toward $\mathrm{Ag}$ ) lead to a high dissolution rate of $\mathrm{Ag}$ NPs compared to a system without thiols (Fig. 5D). It is important to mention that this mechanism needs the participation of a soluble silver thiolate complex; in the opposite case, the thiol ligands will form a passivating layer. Solubility can be dependent of the $\mathrm{pH}$ that will affect the protonation state. Notably, in the case of bound cysteine (where the thiol-thiolate group is not involved in the protonation state), the $\mathrm{pH}$ has to be chosen so that the system is not zwitterionic (and thus neutral) to have an increased solubility. This effect can explain the difference in the dissolution of cysteine-coated Ag NPs [65,100,102,103], as they are performed at different $\mathrm{pH}$. A study of the impact of soluble thiols on the dissolution of NPs, and notably in substoichiometric conditions, remains to our knowledge still to be done.

While a silver oxide layer is the compound that forms primarily during silver oxidation, oxides anions can be displaced in presence of other anions having a higher affinity for silver. This process results in the formation of a layer of another material around the Ag NPs, which will bring a different reactivity. This can result in a stronger passivation, or in a decreased colloidal stability, and impact thus strongly their antibacterial action. Sulfides are particularly notorious, as they are is present in environmental waters and possess a very high affinity for $\mathrm{Ag}(+1)$ to form an almost insoluble $(140 \mu \mathrm{g} / \mathrm{L})$ layer of $\mathrm{Ag}_{2} \mathrm{~S}$. This results in a dramatic diminution of the silver $\left(\mathrm{Ag}^{+}\right.$ions or NPs) antibacterial action in presence of sulfide. Levard et al. showed for instance that when $\mathrm{Ag} \mathrm{Nps}$ and $\mathrm{Na}_{2} \mathrm{~S}$ were mixed, a S/Ag ratio of 0.019 reduced the amount of $\mathrm{Ag}^{+}$released by one order of magnitude. Ag NPs dissolution was suppressed at a ratio of 0.432 ( 0.5 being the stoichiometric conditions) (Fig. 5D) [99].

Halides are another category of anions that will interfere with the passivation layer, while being commonly found in pertinent dissolution media (Fig. 6) [93]. In this case also, one has to take into account the very low solubility of $\mathrm{AgCl}(1.9 \mathrm{mg} / \mathrm{L}), \mathrm{AgBr}(140 \mu \mathrm{g} / \mathrm{L})$ and $\mathrm{Agl}(2.6 \mu \mathrm{g} / \mathrm{L})$ (fluoride ions induce a completely different behavior, as AgF is very 

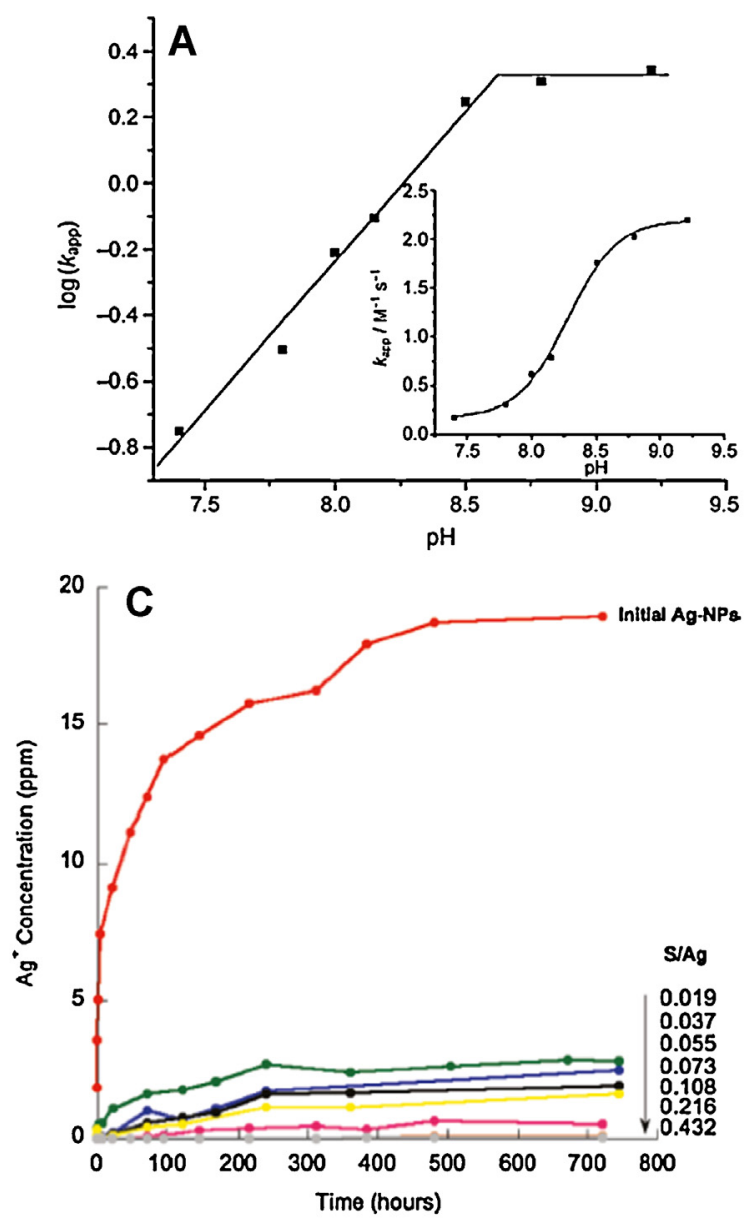
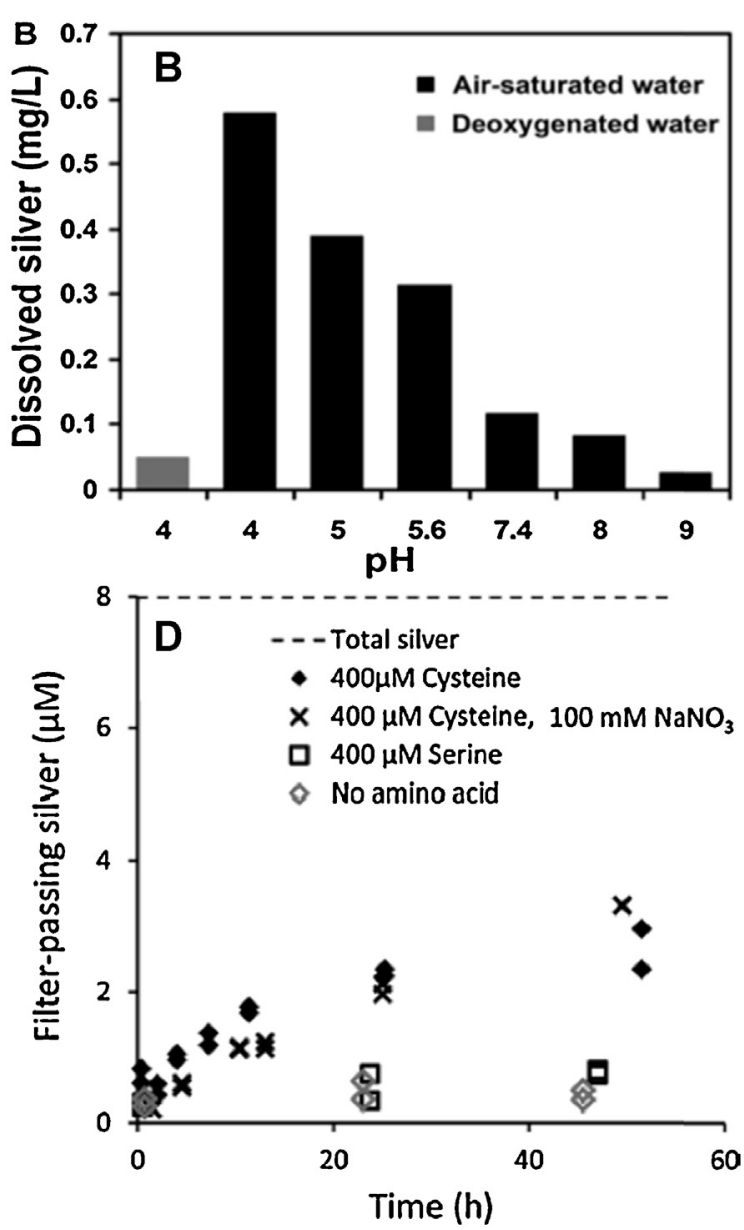

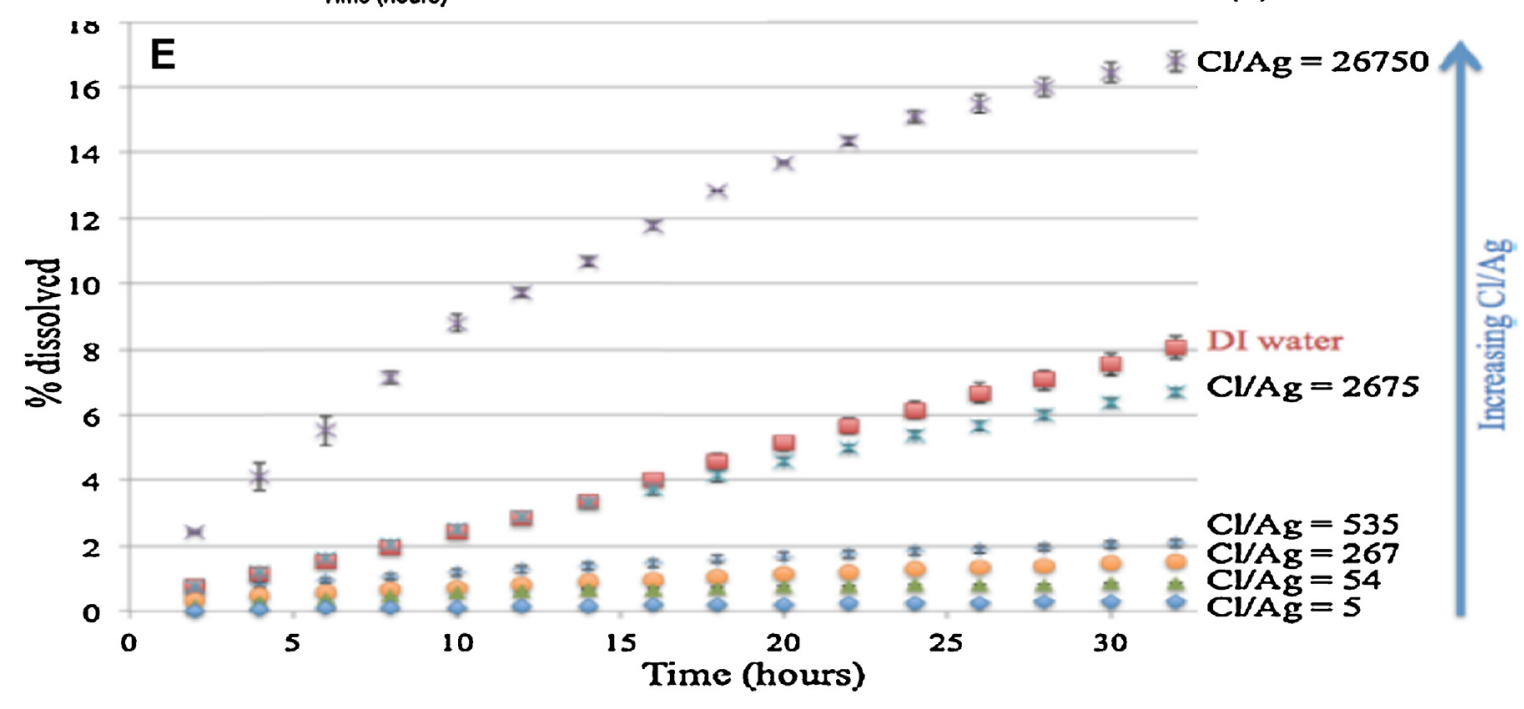

Fig. 5 Dissolution behavior of Ag NPs in presence of other species. (A and B) Dissolution rate of Ag NPs according to the pH in Tris buffer $(A)$ and in a buffer without amines (B). (C-E) Dissolution of Ag NPs in presence of sulfides (C), Cysteine (D) and Chloride (E). (A: Adapted from [95] with permission from John Wiley and Sons, B: Adapted from [97] with permission. Copyright 2010 American Chemical Society, C: Adapted from [99] with permission. Copyright 2011 American Chemical Society, D: Adapted from [100] with permission. Copyright 2012 American Chemical Society, E: Adapted from [60] with permission. Copyright 2013 American Chemical Society).

soluble in water). As such, precipitation of the silver salt at the surface of the Ag NPs or in solution is a phenomenon that has to be taken into account, as well as the potential passivation it involves. By forming silver halide layers around nanoparticles, these anions are also involved in the aggregation phenomenon. However, in the case of chloride, the situation is made different by the existence of silver polychloride complexes $\left[\mathrm{AgCl}_{2}\right]^{-},\left[\mathrm{AgCl}_{3}\right]^{2-}$ and $\left[\mathrm{AgCl}_{4}\right]^{3-}$ that 


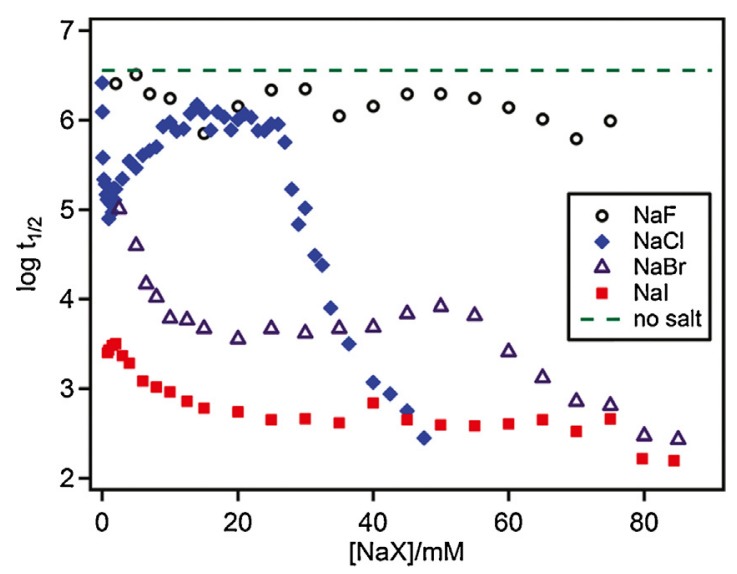

Fig. 6 Evolution of the half-life of Ag NPs in oxidative conditions and in presence of several halides. Diminution of $t_{1 / 2}$ can be due to faster etching or sedimentation.

Adapted from [93] with permission. Copyright 2012 American Chemical Society.

can form if the concentration in chloride is sufficient. These species are soluble in water, and can provide an antibacterial action. As such, Levard et al. [60] showed in 2013 that silver nanoparticles possessed almost no antibacterial effect if the medium contained $0.01 \mathrm{~mol} / \mathrm{L}$ of chloride, while their efficiency was as good as the one in deionized water if the concentration was $0.5 \mathrm{~mol} / \mathrm{L}$ (Fig. $5 \mathrm{E}$ ). This result indicates also that although silver $(+1)$ polychloride complex have an opposite charge of $\mathrm{Ag}^{+}$, both species can disrupt bacterial activity. Silver bromide can also constitute a passivation layer around nanoparticles, although it has been observed to be less impermeable than the $\mathrm{AgCl}$ [93]. Due to its very low solubility, $\mathrm{AgBr}$-polymer composites can be used in systems that require activity over a very long time, such as antifouling. Noticeably, the polymer itself can play a role beyond providing only mechanical stability, and contribute to the dissolution of $\mathrm{AgBr}$, as was observed by Sanbhy et al. with poly-vinylpyridine [36]. Finally, Silver iodide forms also a very insoluble precipitate that scavenges most of the soluble silver species. Interestingly, due to epitaxial mismatch of the hexagonal wurtzite-type Agl and face-centered cubic $\mathrm{Ag}, \mathrm{Agl}$ appeared to be not as passivating as were $\mathrm{AgCl}$ and $\mathrm{AgBr}$ [93].

Along with passivation, aggregation is the other phenomenon that can hinder the activity of antibacterial systems. Aggregates results of the fusing of several nanoparticles, leading to bigger objects that expose less surface (and thus have a lower activity), and that can even be too heavy to be stable as colloids, resulting in a precipitate. The general mechanism of colloidal stability is rather well described by the DLVO theory [104], which states that nanoparticles tends to aggregate due to Van der Walls interaction, unless a layer of ligands create a repulsive potential to counter the attractive one. This repulsion can be of steric nature (coating with polymers, such as polyvinylpyrrolidone (PVP) or uncharged molecules) or of electrostatic natures (coating with charged ligands, such as citrate). One direct consequence is that an increase in the ionic strength of the solution will screen the electrostatic repulsive potential, and lead to the aggregation of the nanoparticles. In a recent study, He et al. [105] considered the ionic strength increase as a parameter that would influence the shape (and fractal dimension) of Ag NPs aggregates. At low ionic strength, a Reaction Limited Cluster Aggregation (RLCA) led to compact aggregates that dissolve slowly, while at higher ionic strength, Diffusion Limited Cluster Aggregation (DLCA) led to more open aggregates and thus to a higher dissolution rate. However, it has to be mentioned that in this study, ionic strength was controlled by adding $\mathrm{NaCl}$, and thus, the soluble polychloride species could play a role in the enhanced dissolution, as mentioned earlier.

Due to their chemical nature, Ag NPs can endure other phenomena that will contribute to cause their aggregation. Noticeably, Ag NPs are often prepared using citrate or PVP ligands that are not strongly bond to the silver surface and can easily be displaced by either molecular (amines, phosphines, thiols, ...) or anionic ligands (oxides, halides, sulfides, ....). These ligands usually provide less colloidal stability and thus lead to the aggregation of the NPs. In the case of ionic ligands, the oxidative dissolution of the nanoparticles leads to the formation of layer of the corresponding silver salt. Layers around two particles have the possibility to fuse, leading to an insoluble bridge between them, and actively contributing to the formation of aggregates, as observed with sulfide [99] and chloride [106]. Divalent cations $\left(\mathrm{Ca}^{2+}, \mathrm{Mg}^{2+}\right)$ have also been observed to cause aggregation of citrate-coated Ag NPs [107]. This effect originates from the formation of a stable citrate-cation chelate complex, removing the stabilizing ligands around the nanoparticle and resulting thus in their aggregation [108].

Activity of Ag NPs can thus be modified by several parameters, either inherent to the nanoparticles (size, shape, coating), or attributable to the medium (presence of light, oxidative species, presence of other potential ligands for silver, ionic strength). These parameters will have an influence on several phenomena that can contribute to the increase or the decrease of the antibacterial activity, along complex pathways, summarized in Fig. 7. Among them, one can cite ligand replacement, oxidative dissolution, $\mathrm{Ag}^{+}$ reduction (chemical or photoinduced), Ag surface passivation, puncturation of the passivation layer, silver speciation and aggregation of the nanoparticles. Furthermore, some chemical species can have an influence on several of these phenomena, such as chloride, which can cause either slower or faster corrosion, depending on its concentration, and aggregation. For these reasons, studies should be performed in controlled conditions to avoid unexpected evolution of the system. As such, Ag NPs should be stored in the dark, in absence of oxygen (selected suspension should be stable for several months in these conditions). Ag NPs evolution should be monitored in controlled conditions, in the dark (except for temporary optical measurements), at controlled Ag concentration, and using reagents that should not have side effects. Most particularly, unless the role of this anion is specifically studied, chloride-containing compound such as $\mathrm{NaCl}$ or $\mathrm{CaCl}_{2}$, should never be used and be replaced if possible by their nitrate or sulfate. Buffering of the solution should if possible be performed in absence of phosphate, carbonate or primary/secondary amine-bearing molecules (Tris, Tricine, TAPS, ...), which interferes with the solubility of $\mathrm{Ag}(+1)$ species. 


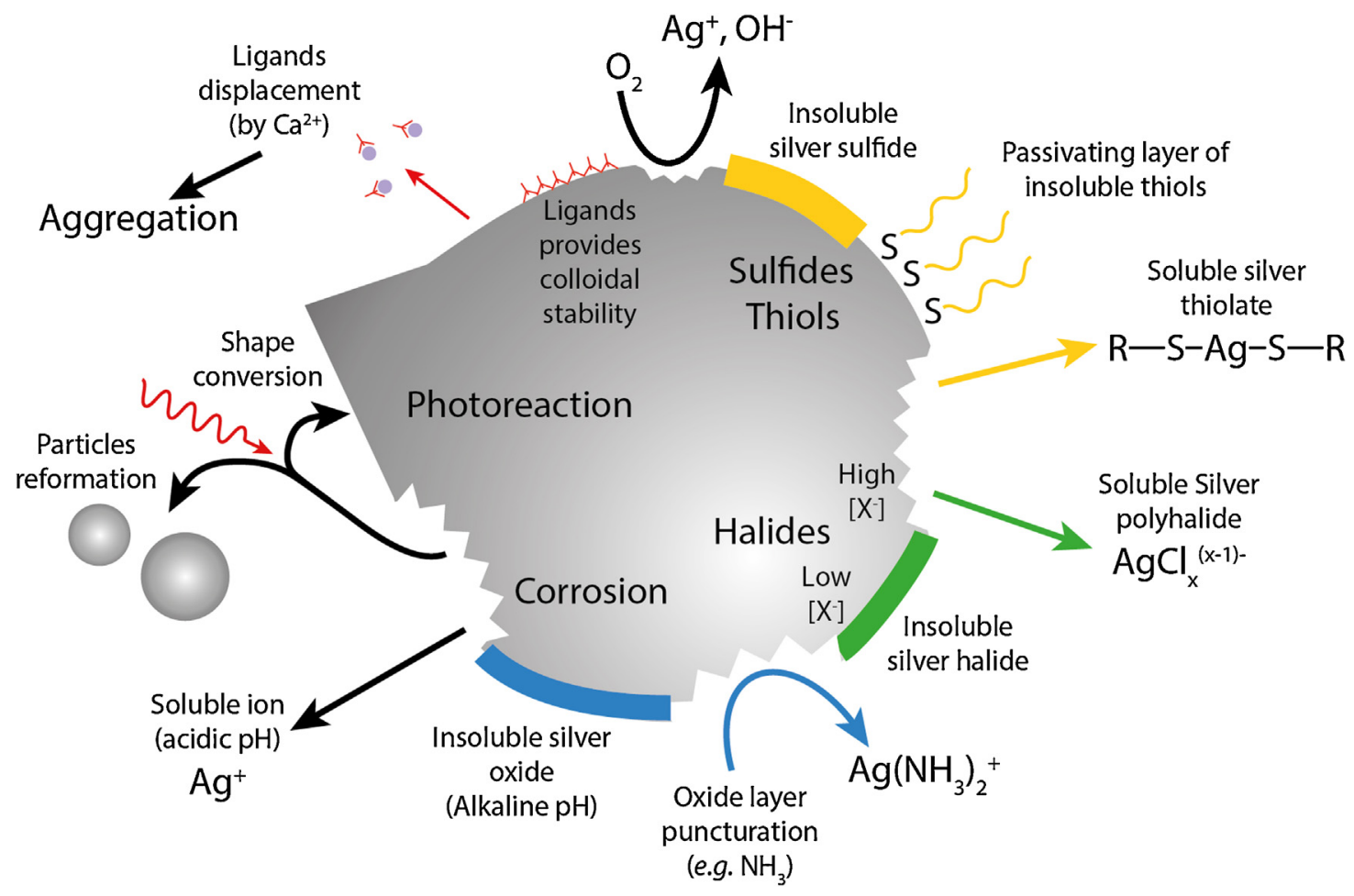

Fig. 7 Visual summary of several phenomena affecting Ag NPs dissolution.

This scheme structure has been inspired by [65].

As we saw, the exact nature of all interactions that Ag NPs have with the surrounding medium is difficult to pinpoints, even in simplified and controlled laboratory conditions. They are consequently much more difficult to clearly assess in real application conditions (either environmental or biological), where the species that can interact with the nanoparticles have a much higher variety and complexity, and where physical conditions such as oximetry, ionic strength or luminosity are not controlled and can vary in different points of the studied system. We will hereby describe briefly some of the phenomena that can occur at the surface of Ag NPs in biologically or environmentally pertinent systems.

\section{Fate of silver nanoparticles in the environment}

With the increasing use of silver-containing disinfection systems rises the concerns of their ecological impact. Silver nanoparticles attached to objects (for instance antibacterial socks) have been shown to be readily released upon washing [109-111]. Once released in the environment, silver may present adverse effect to several categories of organisms, including bacteria, algae, protists, invertebrates and vertebrates [112]. Water filtering animals seem to be especially sensitive to the presence of nanoparticles, due to the high amount of water circulating through gills [113-115]. Presence of silver nanoparticles is also a concern in wastewater treatment, as their antibacterial activity may render the biological degradation process inefficient [116]. It is thus essential to understand clearly the different mechanisms that can be involved in the fate of Ag NPs in the environment, in order to establish a regulation to minimize their environmental impact [117], and to design processes that could be used for the depollution of heavily contaminated effluents [118]. Notably, research is still ongoing to determine whether Ag NPs have a significant impact when they reach wastewater treatment plants [119-121], or if chemical changes (and notably sulfidation) [122,123] inactivate them.

Overall, all the aspect described in sections "Mechanism of action" and "Factors involved in the control of the activity" ' observed in controlled laboratory conditions will still be pertinent in environmental conditions. Oxidative dissolution by dissolved dioxygen will thus still be a major mechanism of silver depletion. Interactions with other species, such as chlorides or sulfides, will once again be a fundamental aspect of the nanoparticles fate. Ion content (notably salinity and hardness), temperature, flow rate and oxygenation of the water are all pertinent parameters to consider when evaluating the fate of nanoparticles.

However, environmental systems present some specificities that will have an influence on the fate of nanoparticulates systems: (i) The presence of dissolved organic matter, constituted of a large variety of molecules and moieties that are not always well-defined, and that can alter the surface chemistry of nanoparticles [124-126]. (ii) Physical and chemical properties can show spatial and temporal disparities in different points of the studied system. For instance, a transition from river to seawater will impact strongly the colloidal and chemical stability of Ag NPs [127]. In addition, seasonal variations can cause temperature shift, and oxygen profile in freshwater can vary temporally and spatially [128]. (iii) Environmental systems contain living 
organisms that can play a role in the distribution and speciation of silver species $[87,112]$. As such, beyond physical chemistry, a study of the fate of Ag NPs in environmental conditions requires to consider several aspects related to other disciplines, such as hydrology and organisms biology. Furthermore, each environmental domain has its specificities, and thus drawing a general scheme may appear reductive in many occasions. As such, establishing a summary of every study done in environmental conditions would fall well beyond the point of this review. We will focus on describing some parameters that present pertinence in term of surface chemistry.

One major difference between a controlled laboratory system and actual environmental conditions is the knowledge of the chemical species in presence. As such, in addition to common ions, natural waters contains a significant quantity of dissolved organic matter (DOM), which includes low to medium molecular weight species as well as macromolecules. This DOM is constituted mostly of aromatic and aliphatic hydrocarbon structure that exhibit amide, carboxyl, hydroxyl, ketones and various minor functions [129]. In an optic of standardization, most studies internationally are performed using DOM (or purified humic acid or fulvic acid fractions) obtained from the Suwannee River [130-132]. These fractions have been shown to adsorb at the surface of nanoparticles, causing their aggregation [130,133] and limiting their $\mathrm{Ag}^{+}$release [97]. Humic acid has also the capability to immobilize $\mathrm{Ag}^{+}$ions and is a mild reducer, leading to the formation of new Ag NPs after dissolution of the original ones [134-136], with influences on the $\mathrm{Ag}^{+}$release dynamics. Additionally, DOM can immobilize other species, such as divalent cations [137]. These species are then less available to contribute to the Ag NPs destabilization, increasing indirectly their stability.

Along with inert DOM, Ag species can interact with living organisms. Beyond the adverse effects this could have for the organisms, it impacts the speciation or distribution of silver in the environment in complex ways, and notably as silver species can enter the trophic chains and be spread among a wide variety of organisms [87]. In particular, most micro-organisms (bacteria, micro-algae and fungi) produce extracellular polymeric substances (EPS) [138]. Ag NPs and $\mathrm{Ag}^{+}$species can be immobilized by these EPS. This contributes to a decrease in the cytotoxicity of metallic ions as they diffuse slowly and progressively toward the cell [139]. Once in the cell, silver species can be further reduced by intracellular metabolites, eliminating the cytotoxicity of the ions while leading to the formation of new silver nanoparticles $[140,141]$.

\section{Interaction with a bacterial culture}

In a similar fashion to environmental media, the surface of nanoparticles can interact with the various constituents of biological incubation media (which have usually an even higher diversity and abundance). This leads to the formation of a protein corona; a layer of adsorbed macromolecules at the surface of nanoparticles [142,143]. This layer is of complex [144] and dynamic nature [145,146], and depends of the composition of the medium as well as the surface properties of the nanoparticles [147-150]. By modifying the surface of nanoparticles, the corona shell can change the interactions they have with cells as well as physical and chemical properties of the systems $[146,151-153]$. In the specific case of Ag NPs, formation of a corona has been shown to increase their colloidal stability in presence of salts [154] and their resistance toward acidic dissolution [155,156]. In 2013, Gnanadhas et al. showed that the presence of proteins in the incubation medium led to a lower antibacterial activity of silver nanoparticles [157]. This study involved blood and serum components, as well as the commonly used Lysogeny Broth (LB), while an activity was kept in minimal medium M9.

One other characteristic of bacterial systems, and one major aspect of their virulence, is their ability to form biofilms [158]. Biofilms are constituted by a community of bacteria that adheres to surfaces through the production of EPS. These structures play a significant role in the resistance of bacterial communities to common antimicrobials (disinfectants, antibiotics, antibodies, ...), by physically protecting the cells at its basis with several layers of bacteria $[159,160]$. In order to be efficient, antibacterial systems thus need to diffuse freely along the biofilm thickness. In the case of metal ions, interaction with functional groups of the EPS matrix, such as amine, thiols or carboxylate, can lead to their immobilization. Mass transfer in the biofilm exhibits thus a non-linear behavior [161]. Mass transfer in the external layers of the biofilm will be slow until most external binding sites are saturated. Afterwards, ions can diffuse progressively toward inner layers [162]. This has for effect to protect the bacteria in the innermost part of the biofilm, as long as an antibacterial threshold concentration is not reached.

In contrast, Ag NPs diffusion is only slightly decreased within biofilms, as far as it can circulate through the meshes of the EPS network. For instance, Peulen et al. [163] determined that the diffusion coefficient in a biofilm remained at $86 \%$ of its value in water of $2 \mathrm{~nm}$ negatively charged Ag NPs. The minor decrease was explained by the tortuosity of the medium. The higher activity of nanoparticles can be explained by a lower immobilization (averaged by the number of atoms) of Ag NPs compared $\mathrm{Ag}^{+}$ions. Surface charge of the nanoparticle and electrostatic interactions were observed to have a negligible role on the NPs diffusion in biofilm, with no retention observed [164]. One condition is however that the NPs diameters are small enough not to be excluded by the EPS network meshes.

As such, while Ag NPs antibacterial action on planktonic cells can be mostly related to their dissolution and effective $\mathrm{Ag}^{+}$, disinfection of biofilm may be a domain where nanoparticles bring a significant advantage. Choi et al. determined that $20 \mathrm{~nm}$ Ag NPs could penetrate a $40 \mu \mathrm{m} E$. coli biofilm within $1 \mathrm{~h}$ [165]. Each Ag NPs diffusing toward the inner part of the biofilm can then dissolve and release several thousands of $\mathrm{Ag}^{+}$atoms, leading to a high activity of the systems against the bacteria in the lower layers of the biofilm [166]. However, this effect was reduced when particles with a low colloidal stability (and thus prone to aggregation) were used, indicating the outermost importance of the Ag NPs surface functionalization for this application. 


\section{Conclusion}

Reactions happening at the surface of Ag NPs are a crucial element to explain their behavior, fate and action, and hence their antibacterial activity. Phenomena that can happen are an oxidative dissolution, formation of a passivating layer, puncturation of this layer by other chemical species, redeposition of silver and formation of bridging material between particles, that leads to their aggregation. In view of the recent literature, there is a strong set of clues indicating the role of $\mathrm{Ag}(+1)$ species as the principal actors to explain $\mathrm{Ag}^{0} \mathrm{NPs}$ antimicrobial effects. Oxidation of the metallic silver core would thus be an essential step of their action mechanism. In conditions allowing their oxidative dissolution, $\mathrm{Ag}^{0} \mathrm{NPs}$ can thus be related to other $\mathrm{Ag}^{+}$-releasing systems, such as salts, zeolites and polymers. This mechanism of $\mathrm{Ag}^{+}$release by NPs explains several aspects of their antimicrobial action. Notably, $\mathrm{Ag}^{0}$ NPs showed to be inactive when washed from residual $\mathrm{Ag}^{+}$ and put in inert atmosphere where no further oxidation can occur. Furthermore, although the primary compound is different, $\mathrm{Ag}^{0}$-based or $\mathrm{Ag}^{+}$release systems possess similar metabolic action. Antibacterial activity is also very sensitive to species that interact with $\mathrm{Ag}^{+}$and form insoluble materials, such as sulfide or chlorides.

In systems where an oxidizer (in most case atmospheric $\mathrm{O}_{2}$ ) is readily accessible, Ag NPs will thus be the best antibacterial silver source, being almost exclusively constituted of this metal. In addition, although not being the active species, $\mathrm{Ag}^{0}$ NPs can bring other advantages, notably by being objects that diffuse as one entity containing several thousands of Ag atoms. Another advantage is that they can adsorb on the bacterial membrane, to deliver locally high quantity of antimicrobial agent.

While each system has its own specificities in terms of composition and targeted organisms, they will all be driven by the chemistry of the $\mathrm{Ag} / \mathrm{Ag}^{+}$species. It is thus very useful to understand deeply the phenomena involved by studying model systems with controlled conditions, before transposing this knowledge to applied cases.

Ag NPs action is highly dependent of their surface reactivity. Smaller nanoparticles, having a higher specific surface, would thus exhibit a higher dissolution rate. It is then of high importance to avoid aggregation of the nanoparticles, as this phenomenon lowers the effective specific surface, and can lead to sedimentation. Formation of a passivation layer is a crucial point in their dissolution kinetics, and small amount of passivating species can be sufficient to stop their dissolution and thus their antibacterial activity. One notable example is $\mathrm{O}_{2}$ that forms a silver oxide layer at the Ag NPs surface. This oxidation is essential for the release of $\mathrm{Ag}(+1)$ species. In mildly acidic conditions $(\mathrm{pH}<5.5)$, this oxide is fairly soluble, but not in neutral and alkaline media, where it will slow down oxidation.

Beyond these physical aspects, Ag NPs action can also be modulated by chemical species. One specificity of silver chemistry is its very high affinity for several compounds frequently found in natural media (either environmental or biological). This includes anions (sulfide, halides, phosphates, ...) and organic molecules (amines and thiols mainly). Divalent cations $\left(\mathrm{Ca}^{2+}\right.$ and $\left.\mathrm{Mg}^{2+}\right)$ can also cause $\mathrm{Ag}$ NPs aggregation, most likely by causing a displacement of their citrate ligand shell. As a consequence, physical chemistry studies around Ag NPs should be realized in absence of these interfering compounds (unless their effect is directly studied). Care should also be taken to control the oxygenation level of the solutions, as well as the illumination. For instance, chloride salts should be replaced by their nitrate (or another anion) counterparts to avoid $\mathrm{AgCl}_{x}{ }^{(x-1)-}$ formation. Buffered solution should not be prepared with molecules that bear primary or secondary amines (such as Tris, TAPS and Tricine), and the $\mathrm{pH}$ should not be adjusted with the addition of $\mathrm{HCl}$. In the opposite case, interpretation of experimental results obtained in inadequate conditions can be very difficult, as several phenomena are to be taken into account. In the case the system's composition cannot be altered and has to contain compounds that will interfere with silver, researchers have to be aware of the possible interferences, and should wisely consider their influence before drawing conclusions.

\section{Acknowledgement}

B.L.O. acknowledges support from the CTI (13945.2), in partnership with Dentsply-Maillefer (Switzerland).

\section{References}

[1] J.S. Kim, E. Kuk, K.N. Yu, J.-H. Kim, S.J. Park, H.J. Lee, S.H Kim, Y.K. Park, Y.H. Park, C.-Y. Hwang, Y.-K. Kim, Y.-S. Lee, D.H. Jeong, M.-H. Cho, Nanomed. Nanotechnol. Biol. Med. 3 (2007) 95

[2] X. Chen, H.J. Schluesener, Toxicol. Lett. 176 (2008) 1

[3] M.A. Fischbach, C.T. Walsh, Science 325 (2009) 1089.

[4] D.I. Andersson, D. Hughes, Nat. Rev. Microbiol. 8 (2010) 260.

[5] A.J. Huh, Y.J. Kwon, J. Controlled Release 156 (2011) 128.

[6] H.H. Lara, E.N. Garza-Treviño, L. Ixtepan-Turrent, D.K. Singh, J. Nanobiotechnol. 9 (2011) 30.

[7] M. Rai, A. Yadav, A. Gade, Biotechnol. Adv. 27 (2009) 76.

[8] M.K. Rai, S.D. Deshmukh, A.P. Ingle, A.K. Gade, J. Appl. Microbiol. 112 (2012) 841.

[9] S. Chernousova, M. Epple, Angew. Chem. Int. Ed. 52 (2013) 1636.

[10] H.J. Klasen, Burns 26 (2000) 117.

[11] H. Klasen, Burns 26 (2000) 131.

[12] I. Sondi, B. Salopek-Sondi, J. Colloid Interface Sci. 275 (2004) 177.

[13] K. Chaloupka, Y. Malam, A.M. Seifalian, Trends Biotechnol. 28 (2010) 580.

[14] B. Reidy, A. Haase, A. Luch, K. Dawson, I. Lynch, Materials 6 (2013) 2295.

[15] H.J. Johnston, G. Hutchison, F.M. Christensen, S. Peters, S. Hankin, V. Stone, Crit. Rev. Toxicol. 40 (2010) 328.

[16] S. Prabhu, E. Poulose, Int. Nano Lett. 2 (2012) 1.

[17] J.A. Lemire, J.J. Harrison, R.J. Turner, Nat. Rev. Microbiol. $11(2013) 371$

[18] D. McShan, P.C. Ray, H. Yu, Nanomater. Toxicol. Med. Appl. $22(2014) 116$

[19] L. Rizzello, P.P. Pompa, Chem. Soc. Rev. 43 (2014) 1501.

[20] C.-N. Lok, C.-M. Ho, R. Chen, Q.-Y. He, W.-Y. Yu, H. Sun, P.H. Tam, J.-F. Chiu, C.-M. Che, JBIC J. Biol. Inorg. Chem. 12 (2007) 527.

[21] Z. Xiu, Q. Zhang, H.L. Puppala, V.L. Colvin, P.J.J. Alvarez, Nano Lett. 12 (2012) 4271.

[22] P.V. AshaRani, G. Low Kah Mun, M.P. Hande, S. Valiyaveettil, ACS Nano 3 (2008) 279. 
[23] S.W.P. Wijnhoven, W.J.G.M. Peijnenburg, C.A. Herberts, W.I. Hagens, A.G. Oomen, E.H.W. Heugens, B. Roszek, J. Bisschops, I. Gosens, D. Van De Meent, S. Dekkers, W.H. De Jong, M. van Zijverden, A.J.A.M. Sips, R.E. Geertsma, Nanotoxicology 3 (2009) 109.

[24] R. de Lima, A.B. Seabra, N. Durán, J. Appl. Toxicol. 32 (2012) 867.

[25] N. Hadrup, H.R. Lam, Regul. Toxicol. Pharmacol. 68 (2014) 1.

[26] S.K. Misra, A. Dybowska, D. Berhanu, S.N. Luoma, E. ValsamiJones, Sci. Total Environ. 438 (2012) 225.

[27] K.-H. Cho, J.-E. Park, T. Osaka, S.-G. Park, Electrochem Micro Nano Technol. EMT 2004 Sel. Pap. 5th Int. Symp. EMT 2004, 29 Sept. to 01 Oct. 2004, Tokyo, Japan 51 (2005) 956.

[28] W.-R. Li, X.-B. Xie, Q.-S. Shi, H.-Y. Zeng, Y.-S. OU-Yang, Y.-B. Chen, Appl. Microbiol. Biotechnol. 85 (2010) 1115.

[29] S. Kim, D.-Y. Ryu, J. Appl. Toxicol. 33 (2013) 78.

[30] O. Choi, Z. Hu, Environ. Sci. Technol. 42 (2008) 4583.

[31] C. Carlson, S.M. Hussain, A.M. Schrand, L.K. Braydich-Stolle, K.L. Hess, R.L. Jones, J.J. Schlager, J. Phys. Chem. B 112 (2008) 13608.

[32] H.-L. Su, C.-C. Chou, D.-J. Hung, S.-H. Lin, I.-C. Pao, J.-H. Lin, F.-L. Huang, R.-X. Dong, J.-J. Lin, Biomaterials 30 (2009) 5979.

[33] H. Xu, F. Qu, H. Xu, W. Lai, Y. Andrew Wang, Z. Aguilar, H. Wei, Biometals 25 (2012) 45.

[34] B. González-Flecha, B. Demple, J. Biol. Chem. 270 (1995) 13681.

[35] J.S. Valentine, D.L. Wertz, T.J. Lyons, L.-L. Liou, J.J. Goto, E.B. Gralla, Curr. Opin. Chem. Biol. 2 (1998) 253.

[36] V. Sambhy, M.M. MacBride, B.R. Peterson, A. Sen, J. Am. Chem. Soc. 128 (2006) 9798.

[37] K. Kawahara, K. Tsuruda, M. Morishita, M. Uchida, Dent. Mater. 16 (2000) 452.

[38] P. Dallas, V.K. Sharma, R. Zboril, Adv. Colloid Interface Sci. 166 (2011) 119.

[39] B.M. Barngrover, C.M. Aikens, J. Phys. Chem. A 115 (2011) 11818.

[40] S.W. Han, S.J. Lee, K. Kim, Langmuir 17 (2001) 6981.

[41] A.N. Parikh, S.D. Gillmor, J.D. Beers, K.M. Beardmore, R.W. Cutts, B.I. Swanson, J. Phys. Chem. B 103 (1999) 2850.

[42] C. Marambio-Jones, E.M.V. Hoek, J. Nanopart. Res. 12 (2010) 1531.

[43] J.M. Campos-Martin, G. Blanco-Brieva, J.L.G. Fierro, Angew. Chem. Int. Ed. 45 (2006) 6962.

[44] Y. Matsumura, K. Yoshikata, S.-i. Kunisaki, T. Tsuchido, Appl. Environ. Microbiol. 69 (2003) 4278.

[45] H.-J. Park, J.Y. Kim, J. Kim, J.-H. Lee, J.-S. Hahn, M.B. Gu, J. Yoon, Water Res. 43 (2009) 1027.

[46] Y. Li, W. Zhang, J. Niu, Y. Chen, Environ. Sci. Technol. 47 (2013) 10293.

[47] J.M. Matés, Toxicology 153 (2000) 83.

[48] M.J. Piao, K.A. Kang, I.K. Lee, H.S. Kim, S. Kim, J.Y. Choi, J. Choi, J.W. Hyun, Toxicol. Lett. 201 (2011) 92.

[49] K. Loza, J. Diendorf, C. Sengstock, L. Ruiz-Gonzalez, J.M. Gonzalez-Calbet, M. Vallet-Regi, M. Koller, M. Epple, J. Mater. Chem. B 2 (2014) 1634.

[50] J. Gibbard, J. Am, Public Health Nations Health 27 (1937) 112.

[51] S.S. Djokić, R.E. Burrell, J. Electrochem. Soc. 145 (1998) 1426.

[52] S. Kittler, C. Greulich, J. Diendorf, M. Köller, M. Epple, Chem. Mater. 22 (2010) 4548.

[53] Y. Yang, Q. Chen, J.D. Wall, Z. Hu, Water Res. 46 (2012) 1176.

[54] J. Dobias, R. Bernier-Latmani, Environ. Sci. Technol. 47 (2013) 4140.

[55] A. Henglein, Chem. Mater. 10 (1998) 444.

[56] Z.-M. Xiu, J. Ma, P.J.J. Alvarez, Environ. Sci. Technol. 45 (2011) 9003
[57] O. Choi, T.E. Clevenger, B. Deng, R.Y. Surampalli, L. Ross Jr., Z. Hu, Water Res. 43 (2009) 1879.

[58] B.C. Reinsch, C. Levard, Z. Li, R. Ma, A. Wise, K.B. Gregory, G.E. Brown, G.V. Lowry, Environ. Sci. Technol. 46 (2012) 6992.

[59] C. Levard, E.M. Hotze, B.P. Colman, A.L. Dale, L. Truong, X.Y. Yang, A.J. Bone, G.E. Brown, R.L. Tanguay, R.T. Di Giulio, E.S. Bernhardt, J.N. Meyer, M.R. Wiesner, G.V. Lowry, Environ. Sci. Technol. 47 (2013) 13440.

[60] C. Levard, S. Mitra, T. Yang, A.D. Jew, A.R. Badireddy, G.V. Lowry, G.E. Brown, Environ. Sci. Technol. (2013).

[61] B.A. Chambers, A.R.M.N. Afrooz, S. Bae, N. Aich, L. Katz, N.B. Saleh, M.J. Kirisits, Environ. Sci. Technol. 48 (2013) 761.

[62] S. Pal, Y.K. Tak, J.M. Song, Appl. Environ. Microbiol. 73 (2007) 1712.

[63] W. Zhang, Y. Yao, N. Sullivan, Y. Chen, Environ. Sci. Technol. 45 (2011) 4422.

[64] E. Bae, H.-J. Park, J. Lee, Y. Kim, J. Yoon, K. Park, K. Choi, J. Yi, Environ. Toxicol. Chem. 29 (2010) 2154.

[65] J. Liu, D.A. Sonshine, S. Shervani, R.H. Hurt, ACS Nano 4 (2010) 6903.

[66] B. Sadeghi, F.S. Garmaroudi, M. Hashemi, H.R. Nezhad, A. Nasrollahi, S. Ardalan, S. Ardalan, Adv. Powder Technol. 23 (2012) 22.

[67] J.R. Morones, J.L. Elechiguerra, A. Camacho, K. Holt, J.B. Kouri, J.T. Ramírez, M.J. Yacaman, Nanotechnology 16 (2005) 2346.

[68] J. Schnadt, J. Knudsen, X.L. Hu, A. Michaelides, R.T. Vang, K. Reuter, Z. Li, E. Lægsgaard, M. Scheffler, F. Besenbacher, Phys. Rev. B 80 (2009) 075424.

[69] E.-J. Park, J. Yi, Y. Kim, K. Choi, K. Park, Toxicol. In Vitro 24 (2010) 872.

[70] A. Ivask, A. ElBadawy, C. Kaweeteerawat, D. Boren, H. Fischer, Z. Ji, C.H. Chang, R. Liu, T. Tolaymat, D. Telesca, J.I. Zink, Y. Cohen, P.A. Holden, H.A. Godwin, ACS Nano 8 (2013) 374.

[71] A.M. El Badawy, R.G. Silva, B. Morris, K.G. Scheckel, M.T. Suidan, T.M. Tolaymat, Environ. Sci. Technol. 45 (2010) 283.

[72] M. Banerjee, S. Mallick, A. Paul, A. Chattopadhyay, S.S. Ghosh, Langmuir 26 (2010) 5901.

[73] L. Kvítek, A. Panáček, J. Soukupová, M. Kolář, R. Večeřová, R. Prucek, M. Holecová, R. Zbořil, J. Phys. Chem. C 112 (2008) 5825.

[74] S. Ruden, K. Hilpert, M. Berditsch, P. Wadhwani, A.S. Ulrich, Antimicrob. Agents Chemother. 53 (2009) 3538.

[75] J.R. Morones-Ramirez, J.A. Winkler, C.S. Spina, J.J. Collins, Sci. Transl. Med. 5 (2013) 190ra81.

[76] N. Lewinski, V. Colvin, R. Drezek, Small 4 (2008) 26.

[77] A.M. Schrand, H. Huang, C. Carlson, J.J. Schlager, E. Ōsawa, S.M. Hussain, L. Dai, J. Phys. Chem. B 111 (2006) 2.

[78] T.J. Brunner, P. Wick, P. Manser, P. Spohn, R.N. Grass, L.K. Limbach, A. Bruinink, W.J. Stark, Environ. Sci. Technol. 40 (2006) 4374.

[79] W. Jiang, H. Mashayekhi, B. Xing, Spec. Issue Sect. Ozone Mediterr, Ecol. Plants People Probl. 157 (2009) 1619.

[80] R. Jin, Y. Cao, C.A. Mirkin, K.L. Kelly, G.C. Schatz, J.G. Zheng, Science 294 (2001) 1901.

[81] C. Xue, G.S. Métraux, J.E. Millstone, C.A. Mirkin, J. Am. Chem. Soc. 130 (2008) 8337.

[82] C. Xue, J.E. Millstone, S. Li, C.A. Mirkin, Angew. Chem. Int. Ed. 46 (2007) 8436.

[83] C. Xue, C.A. Mirkin, Angew. Chem. 119 (2007) 2082.

[84] J. An, B. Tang, X. Zheng, J. Zhou, F. Dong, S. Xu, Y. Wang, B. Zhao, W. Xu, J. Phys. Chem. C 112 (2008) 15176.

[85] R.D. Glover, J.M. Miller, J.E. Hutchison, ACS Nano 5 (2011) 8950.

[86] S. Yu, Y. Yin, J. Chao, M. Shen, J. Liu, Environ. Sci. Technol. 48 (2013) 403. 
[87] W.-C. Hou, P. Westerhoff, J.D. Posner, Environ. Sci. Process, Impacts 15 (2013) 103.

[88] W. Ostwald, Z. Für, Phys. Chem. 34 (1900) 495.

[89] W. Wu, G. Nancollas, J. Solution Chem. 27 (1998) 521.

[90] R. Müller, C. Jacobs, O. Kayser, Nanopart. Syst. Improv. Drug Deliv. 47 (2001) 3.

[91] R. Ma, C. Levard, S.M. Marinakos, Y. Cheng, J. Liu, F.M. Michel, G.E. Brown, G.V. Lowry, Environ. Sci. Technol. 46 (2011) 752.

[92] J.D. Rimer, O. Trofymluk, A. Navrotsky, R.F. Lobo, D.G. Vlachos, Chem. Mater. 19 (2007) 4189.

[93] M.G. Espinoza, M.L. Hinks, A.M. Mendoza, D.P. Pullman, K.I. Peterson, J. Phys. Chem. C 116 (2012) 8305.

[94] C.M. Aikens, J. Phys. Chem. Lett. 2 (2010) 99.

[95] C.-M. Ho, C.-K. Wong, S.K.-W. Yau, C.-N. Lok, C.-M. Che, Chem. Asian J. 6 (2011) 2506.

[96] C. Kostigen Mumper, A.-K. Ostermeyer, L. Semprini, T.S. Radniecki, Chemosphere 93 (2013) 2493.

[97] J. Liu, R.H. Hurt, Environ. Sci. Technol. 44 (2010) 2169.

[98] T.S. Peretyazhko, Q. Zhang, V.L. Colvin, Environ. Sci. Technol. 48 (2014) 11954.

[99] C. Levard, B.C. Reinsch, F.M. Michel, C. Oumahi, G.V. Lowry, G.E. Brown, Environ. Sci. Technol. 45 (2011) 5260.

[100] A.P. Gondikas, A. Morris, B.C. Reinsch, S.M. Marinakos, G.V. Lowry, H. Hsu-Kim, Environ. Sci. Technol. 46 (2012) 7037.

[101] G.A. Sotiriou, A. Meyer, J.T.N. Knijnenburg, S. Panke, S.E. Pratsinis, Langmuir 28 (2012) 15929.

[102] E. Navarro, F. Piccapietra, B. Wagner, F. Marconi, R. Kaegi, N. Odzak, L. Sigg, R. Behra, Environ. Sci. Technol. 42 (2008) 8959.

[103] K. Siriwardana, A. Wang, M. Gadogbe, W.E. Collier, N.C. Fitzkee, D. Zhang, J. Phys. Chem. C 119 (2015) 2910.

[104] W.B. Russel, D.A. Saville, W.R. Schowalter, Colloidal Dispersions, Cambridge University Press, Cambridge, 1989.

[105] D. He, M.W. Bligh, T.D. Waite, Environ. Sci. Technol. 47 (2013) 9148.

[106] X. Li, J.J. Lenhart, Environ. Sci. Technol. 46 (2012) 5378.

[107] M. Baalousha, Y. Nur, I. Römer, M. Tejamaya, J.R. Lead, Sci. Total Environ. 454-455 (2013) 119.

[108] K.A. Huynh, K.L. Chen, Environ. Sci. Technol. 45 (2011) 5564.

[109] T.M. Benn, P. Westerhoff, Environ. Sci. Technol. 42 (2008) 4133.

[110] F. Gottschalk, B. Nowack, J. Environ. Monit. 13 (2011) 1145.

[111] D.M. Mitrano, E. Rimmele, A. Wichser, R. Erni, M. Height, B. Nowack, ACS Nano 8 (2014) 7208.

[112] J. Fabrega, S.N. Luoma, C.R. Tyler, T.S. Galloway, J.R. Lead, Environ. Int. 37 (2011) 517.

[113] R.J. Griffitt, K. Hyndman, N.D. Denslow, D.S. Barber, Toxicol. Sci. 107 (2009) 404.

[114] J. Farkas, P. Christian, J.A. Gallego-Urrea, N. Roos, M. Hassellöv, K.E. Tollefsen, K.V. Thomas, Aquat. Toxicol. 101 (2011) 117.

[115] M. Zuykov, E. Pelletier, S. Demers, Mar. Environ. Res. 71 (2011) 17.

[116] N. Musee, M. Thwala, N. Nota, J. Environ. Monit. 13 (2011) 1164.

[117] T. Faunce, A. Watal, Nanomedicine 5 (2010) 617.

[118] Q. Sun, Y. Li, T. Tang, Z. Yuan, C.-P. Yu, J. Hazard. Mater. 261 (2013) 414.

[119] L. Hou, K. Li, Y. Ding, Y. Li, J. Chen, X. Wu, X. Li, Chemosphere 87 (2012) 248.

[120] S. Eduok, B. Martin, R. Villa, A. Nocker, B. Jefferson, F. Coulon, Ecotoxicol. Environ. Saf. 95 (2013) 1.

[121] R. Ma, C. Levard, J.D. Judy, J.M. Unrine, M. Durenkamp, B. Martin, B. Jefferson, G.V. Lowry, Environ. Sci. Technol. 48 (2014) 104.
[122] R. Kaegi, A. Voegelin, C. Ort, B. Sinnet, B. Thalmann, J. Krismer, H. Hagendorfer, M. Elumelu, E. Mueller, Nanotechnol. Water Wastewater Treat. 47 (2013) 3866.

[123] R.D. Kent, J.G. Oser, P.J. Vikesland, Environ. Sci. Technol. 48 (2014) 8564.

[124] C. Levard, E.M. Hotze, G.V. Lowry, G.E. Brown, Environ. Sci. Technol. 46 (2012) 6900.

[125] S. Yu, Y. Yin, J. Liu, Environ. Sci. Process, Impacts 15 (2013) 78.

[126] A. Philippe, G.E. Schaumann, Environ. Sci. Technol. 48 (2014) 8946.

[127] M. Filella, J. Buffle, Collect. Pap. Present. Int. Symp. Colloids Aquat. Environ. Organ. SCI Surf. Chem. Group 73 (1993) 255.

[128] H.G. Stefan, X. Fang, Ecol. Model. 71 (1994) 37.

[129] A. Nebbioso, A. Piccolo, Anal. Bioanal. Chem. 405 (2013) 109.

[130] J. Gao, K. Powers, Y. Wang, H. Zhou, S.M. Roberts, B.M. Moudgil, B. Koopman, D.S. Barber, Chemosphere 89 (2012) 96.

[131] J. Gao, S. Youn, A. Hovsepyan, V.L. Llaneza, Y. Wang, G. Bitton, J.-C.J. Bonzongo, Environ. Sci. Technol. 43 (2009) 3322.

[132] R.F. Domingos, N. Tufenkji, K.J. Wilkinson, Environ. Sci. Technol. 43 (2009) 1282.

[133] L.R. Pokhrel, B. Dubey, P.R. Scheuerman, Environ. Sci. Technol. 47 (2013) 12877.

[134] N. Akaighe, R.I. MacCuspie, D.A. Navarro, D.S. Aga, S. Banerjee, M. Sohn, V.K. Sharma, Environ. Sci. Technol. 45 (2011) 3895.

[135] W.-C. Hou, B. Stuart, R. Howes, R.G. Zepp, Environ. Sci. Technol. 47 (2013) 7713.

[136] N.F. Adegboyega, V.K. Sharma, K. Siskova, R. Zbořil, M. Sohn, B.J. Schultz, S. Banerjee, Environ. Sci. Technol. 47 (2012) 757.

[137] Y. Kunhi Mouvenchery, J. Kučerík, D. Diehl, G. Schaumann, Rev. Environ. Sci. Biotechnol. 11 (2012) 41.

[138] F. Kang, P.J. Alvarez, D. Zhu, Environ. Sci. Technol. 48 (2013) 316.

[139] A.-J. Miao, K.A. Schwehr, C. Xu, S.-J. Zhang, Z. Luo, A. Quigg, P.H. Santschi, Environ. Pollut. 157 (2009) 3034.

[140] K.B. Narayanan, N. Sakthivel, Adv. Colloid Interface Sci. 156 (2010) 1.

[141] G.S. Dhillon, S.K. Brar, S. Kaur, M. Verma, Crit. Rev. Biotechnol. 32 (2011) 49.

[142] I. Lynch, K.A. Dawson, Nano Today 3 (2008) 40.

[143] A.E. Nel, L. Madler, D. Velegol, T. Xia, E.M.V. Hoek, P. Somasundaran, F. Klaessig, V. Castranova, M. Thompson, Nat. Mater. 8 (2009) 543.

[144] J.H. Shannahan, X. Lai, P.C. Ke, R. Podila, J.M. Brown, F.A. Witzmann, PLOS ONE 8 (2013) e74001.

[145] E. Casals, T. Pfaller, A. Duschl, G.J. Oostingh, V. Puntes, ACS Nano 4 (2010) 3623.

[146] M.P. Monopoli, C. Aberg, A. Salvati, K.A. Dawson, Nat. Nano 7 (2012) 779.

[147] M. Lundqvist, J. Stigler, G. Elia, I. Lynch, T. Cedervall, K.A. Dawson, Proc. Natl. Acad. Sci. U. S. A. 105 (2008) 14265.

[148] R. Huang, R.P. Carney, F. Stellacci, B.L.T. Lau, Nanoscale 5 (2013) 6928.

[149] R. Eigenheer, E.R. Castellanos, M.Y. Nakamoto, K.T. Gerner, A.M. Lampe, K.E. Wheeler, Environ. Sci. Nano 1 (2014) 238.

[150] R. Huang, R.P. Carney, K. Ikuma, F. Stellacci, B.L.T. Lau, ACS Nano 8 (2014) 5402.

[151] D. Walczyk, F.B. Bombelli, M.P. Monopoli, I. Lynch, K.A. Dawson, J. Am. Chem. Soc. 132 (2010) 5761.

[152] M.P. Monopoli, D. Walczyk, A. Campbell, G. Elia, I. Lynch, F. Baldelli Bombelli, K.A. Dawson, J. Am. Chem. Soc. 133 (2011) 2525.

[153] A. Lesniak, F. Fenaroli, M.P. Monopoli, C. Åberg, K.A. Dawson, A. Salvati, ACS Nano 6 (2012) 5845. 
[154] J.S. Gebauer, M. Malissek, S. Simon, S.K. Knauer, M. Maskos, R.H. Stauber, W. Peukert, L. Treuel, Langmuir 28 (2012) 9673.

[155] M.N. Martin, A.J. Allen, R.I. MacCuspie, V.A. Hackley, Langmuir 30 (2014) 11442.

[156] J.-T. Tai, C.-S. Lai, H.-C. Ho, Y.-S. Yeh, H.-F. Wang, R.-M. Ho, D.-H. Tsai, Langmuir 30 (2014) 12755.

[157] D.P. Gnanadhas, M. Ben Thomas, R. Thomas, A.M. Raichur, D. Chakravortty, Antimicrob. Agents Chemother. 57 (2013) 4945.

[158] M.R. Parsek, P.K. Singh, Annu. Rev. Microbiol. 57 (2003) 677.

[159] J.W. Costerton, P.S. Stewart, E.P. Greenberg, Science 284 (1999) 1318.

[160] H.-C. Flemming, J. Wingender, Nat. Rev. Microbiol. 8 (2010) 623.

[161] P.S. Stewart, J. Bacteriol. 185 (2003) 1485.

[162] E. van Hullebusch, M. Zandvoort, P.L. Lens, Rev. Environ. Sci. Biotechnol. 2 (2003) 9.

[163] T.-O. Peulen, K.J. Wilkinson, Environ. Sci. Technol. 45 (2011) 3367.

[164] M. Golmohamadi, R.J. Clark, J.G.C. Veinot, K.J. Wilkinson, Environ. Chem. 10 (2013) 34

[165] O. Choi, C.-P. Yu, G. Esteban Fernández, Z. Hu, Water Res. 44 (2010) 6095

[166] S.M. Wirth, G.V. Lowry, R.D. Tilton, Environ. Sci. Technol. 46 (2012) 12687.

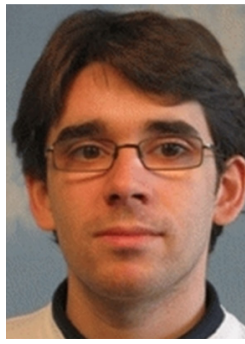

Benjamin Le Ouay received in 2012 his $\mathrm{PhD}$ in Materials Chemistry from the University of Paris 6-Pierre et Marie Curie, France, under the supervision of Pr. C. Laberty-Robert and Pr. T. Coradin. Currently, he is working as a post-doctoral researcher at Ecole Polytechnique Fédérale de Lausanne, Switzerland, under the supervision of Pr. F. Stellacci. He focuses on the physical-chemistry and electrochemical characterization of materials at the interface with living micro-organisms.

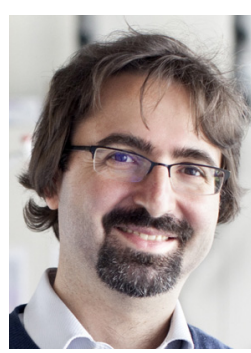

Francesco Stellacci graduated in Materials Engineering at the Politecnico di Milano, Italy. After a post-doctoral experience in the Chemistry Department at the University of Arizona, Tucson, USA, he was appointed assistant professor in 2002 in the Department of Materials Science and Engineering at the Massachusetts Institute of Technology. Since 2010, he is a full professor, Constellium Chair, in the Institute of Materials, at the Ecole Polytechnique Fédérale de Lausanne, Switzerland, where he is the head of the Supramolecular Nanomaterials and Interfaces Laboratory. He has been the Director of the Integrative Food and Nutrition Center in Lausanne since 2014. 